Western University

Scholarship@Western

Biology Publications

Biology Department

$2-2015$

\title{
Cold truths: how winter drives responses of terrestrial organisms to climate change
}

Caroline M. Williams

University of Florida

Hugh A.L. Henry

Western University

Brent J. Sinclair

Western University, bsincla7@uwo.ca

Follow this and additional works at: https://ir.lib.uwo.ca/biologypub

Part of the Biology Commons, Ecology and Evolutionary Biology Commons, and the Entomology Commons

Citation of this paper:

Williams, C. M., Henry, H. A. L. and Sinclair, B. J. (2015), Cold truths: how winter drives responses of terrestrial organisms to climate change. Biol Rev, 90: 214-235. doi:10.1111/brv.12105 


\section{BIOLOGICAL REVIEWS \\ Cambridge \\ Philosophical Society}

\section{Cold truths: How winter drives responses of terrestrial organisms to climate change}

\begin{tabular}{|c|c|}
\hline Journal: & Biological Reviews \\
\hline Manuscript ID: & Draft \\
\hline Manuscript Type: & Original Article \\
\hline Date Submitted by the Author: & $n / a$ \\
\hline Complete List of Authors: & $\begin{array}{l}\text { Williams, Caroline; University of Florida, Entomology and Nematology } \\
\text { Henry, Hugh; Western University, Biology } \\
\text { Sinclair, Brent; Western University, Biology }\end{array}$ \\
\hline Keywords: & $\begin{array}{l}\text { snow, frost, cold, extreme events, average temperatures, freeze-thaw } \\
\text { cycles, sub-lethal impacts, energetics, hibernation }\end{array}$ \\
\hline & $\begin{array}{c}\text { SCHOLARONE } \\
\text { Manuscripts }\end{array}$ \\
\hline
\end{tabular}


1

2 Cold truths: How winter drives responses of terrestrial organisms to climate 3 change

4

5 Caroline M. Williams ${ }^{1}$, Hugh A.L. Henry ${ }^{2}$ \& Brent J. Sinclair ${ }^{2}$

$6{ }^{1}$ Department of Entomology and Nematology, University of Florida, Gainesville, FL, USA

$7 \quad{ }^{2}$ Department of Biology, The University of Western Ontario, London, ON, Canada

8

9 Running Title: Organismal responses to winter climate change 10

11

15

This is the pre-peer reviewed version of the following article: Williams, C. M., Henry, H. A. L. and Sinclair, B. J. (2015), Cold truths: how winter drives responses of terrestrial organisms to climate change. Biol Rev, 90: 214-235. doi:10.1111/brv.12105, which has been published in final form at 10.1111/brv.12105. This article may be used for non-commercial purposes in accordance with Wiley Terms and Conditions for SelfArchiving 


\section{Abstract}

21 Winter is a key driver of individual performance, community composition, and ecological

22 interactions in terrestrial habitats. Although climate change research tends to focus on

23 performance in the growing season, climate change is also modifying winter conditions rapidly.

24 Changes to winter temperatures, the variability of winter conditions, and winter snow cover can

25 interact to induce cold injury, alter energy and water balance, advance or retard phenology, and

26 modify community interactions. Species vary in their susceptibility to these winter drivers,

27 hampering efforts to predict biological responses to climate change. Existing frameworks for

28 predicting the impacts of climate change do not incorporate the complexity of organismal

29 responses to winter. Here, we synthesise organismal responses to winter climate change, and use

30 this synthesis to build a framework to predict exposure and sensitivity to negative impacts, and

31 that can be used to estimate the vulnerability of species to winter climate change. We describe

32 the importance of relationships between winter conditions and performance during the growing

33 season in determining fitness, and demonstrate how summer and winter processes are linked.

34 Incorporating winter into current models will require concerted effort from theoreticians and

35 empiricists, and the expansion of current growing season studies to incorporate winter. 
37 Contents

38 I. Introduction

39 II. Winter climate change

III. Mechanistic bases of the biological impacts of winter climate change

(1) Increased average winter temperatures

(a) Effects on metabolic rate

(b) Effects on development and phenology

(2) Altered thermal variability

(a) Intensity and regularity of winter extremes

(b) Frequency of threshold-crossing events

(c) Impacts of the amplitude of thermal cycles

49 IV. Links between winter and summer responses to climate change

50 V. Scaling up to populations, communities, and ecosystems

51 VI. Predicting vulnerability to winter climate change

52 VII. A call to further integrate winter into climate change research

53 VIII. Conclusions

54 IX. Acknowledgements

55 X. References 


\section{Introduction}

Terrestrial organisms in temperate, alpine and polar environments may spend more than half their lives overwintering. In these habitats, winter is the period during which sustained low temperatures (usually below freezing) occur. Winter conditions vary geographically more than summer conditions (Bonan, 2003), and thus can delineate latitudinal variation in biological processes more starkly than conditions in the growing season. For example, the respective extreme maximum temperatures recorded in Montreal, Quebec $\left(45^{\circ} \mathrm{N}\right)$ in Canada, and Miami, Florida $\left(25^{\circ} \mathrm{N}\right)$ in the United States over the $1997-2000$ period are $36.1^{\circ} \mathrm{C}$ and $36.7^{\circ} \mathrm{C}$, whereas the respective extreme minimum temperatures at these locations, $-37.8^{\circ} \mathrm{C}$ and $-1.1{ }^{\circ} \mathrm{C}$, differ dramatically (data from NOAA National Climatic Data Centre (USA) www.ncdc.noaa.gov and Environment Canada climate.weather.gc.ca). Extreme low winter temperatures constrain the geographic distributions of many species, presented most graphically in the plant hardiness zones used by gardeners and farmers: data on frost susceptibility is a key component underlying these maps (Daly et al., 2012). Winter temperatures that directly cause mortality limit the northern distributions of organisms as diverse as the Virginia opossum in eastern North America (Kanda, 2005), the mountain pine beetle in western North America (Stahl, Moore \& McKendry, 2006), and citrus crops worldwide (Spiegel-Roy \& Goldschmidt, 2008). Winter also poses indirect challenges. Many organisms overwinter in dormancy (and therefore cannot replenish energy reserves until spring). Those organisms that remain active face resource shortages, which may be compounded by the physical barriers presented by snow and ice and the increased cost of thermoregulation. Energetic deficits accrued during the winter can lead to mortality or reduce subsequent fecundity (Hahn \& Denlinger, 2011; Irwin \& Lee, 2003), and overwintering energetics constrain some species' distributions (e.g. Humphries, Thomas \& Speakman, 2002). 
81 In spite of the constraints, many species thrive in places with severe winters, and there

82 are species that might be considered winter-dependent; for example, most Arctic vertebrates

83 require snow and ice for their reproduction and survival (Gilg et al., 2012), and some

84 invertebrates disperse and hunt primarily in subnivean (beneath the snow pack) spaces

85 (Addington \& Seastedt, 1999; Pauli et al., 2013). Some species that overwinter in a dormant

86 state have evolved dependence on winter cues for termination of dormancy (Amasino, 2004;

87 Tauber, Tauber \& Masaki, 1986), and monarch butterflies rely on winter cold to reverse the

88 direction of their fall migration (Guerra \& Reppert, 2013). Many ectotherms and hibernating

89 mammals rely on low winter temperatures to reduce consumption of energy stores (Humphries et

90 al., 2002; Williams et al., 2012b). At the ecosystem level, freezing of soil in winter can mobilise

91 nutrients (and/or damage roots), affecting nutrient availability and uptake, and therefore primary

92 productivity, in the spring (Durán et al., 2013; Groffman et al., 2001). Likewise, winter

93 conditions in many species can define organismal performance in the subsequent summer (Boggs

94 \& Inouye, 2012; Post et al., 1997; Serrano et al., 2011).

95 Repeated glacial/interglacial cycles, coupled with continental drift in and out of the

96 tropics, mean that physiological and life history adaptations to winter have evolved repeatedly in

97 multiple lineages of organisms. The evolutionary impact of winter on life histories is significant

98 - for example, the northern temperate winter may have been a primary driver of the evolution of

99 migratory and hibernation phenotypes (Alerstam, Hedenstrom \& Akesson, 2003; Turbill, Bieber

$100 \&$ Ruf, 2011). For ectotherms, microbes, and plants, the threat of internal ice formation has

101 driven the evolution of physiological traits that allow them to resist low temperatures (for

102 example, freeze tolerance in insects and plants; Margesin, Neuner \& Storey, 2007).

103 Nevertheless, both endotherms and ectotherms suffer high mortality over winter (Hodges, 
104 Boonstra \& Krebs, 2006; Roland \& Matter, 2013; Stahl et al., 2006), and the population

105 dynamics of diverse fast-reproducing animals including lemmings and moths can be driven

106 primarily by winter mortality (Callaghan et al., 2004; Virtanen, Neuvonen \& Nikula, 1998).

107 Anthropogenic climate change is rapidly altering biological systems, and winter

108 conditions are changing particularly rapidly (IPCC, 2007). Differential sensitivity of organisms

109 to climate change is restructuring biological communities due to disparate range and phenology

110 shifts, and altered population dynamics (Chen et al., 2011a; Walther, 2010), and - where the

111 proximate cause is known - many biological responses to climate change are driven by changes

112 in winter conditions (e.g. Battisti et al., 2005; Crozier, 2004). To guide mitigation efforts under

113 global climate change, we must identify which species or populations will be "winners" -

114 benefitting from climate change, and which "losers" will be vulnerable to changes (Somero,

115 2010). However, the interactions between snow and temperature that determine microclimate

116 conditions combine with divergent ecological and physiological strategies for dealing with

117 winter stress, leading to variation among species in responses to winter climate change. In some

118 cases, these idiosyncratic responses to winter likely underlie the failure of models to accurately

119 predict species' responses to climate change (Cook, Wolkovich \& Parmesan, 2012). A limited

120 understanding of organismal responses to winter climate change (and their cascading effects

121 through communities and ecosystems) thus impedes efforts to predict the biological impacts of

122 climate change in general.

123 The interaction between a species' traits (and the plasticity of those traits; Chown et al.,

124 2007; Somero, 2010) and changes in the abiotic environment will determine success or failure in

125 a changing world (Foden et al., 2013), so predictions would ideally utilise information on species

126 traits combined with climate models to output vulnerability. Meta-analyses have shed some light 
127 on the relationship between species' traits and their responses to environmental change (e.g.

128 Bokhorst et al., 2012a; Diamond et al., 2011; Jiguet et al., 2007; Thackeray et al., 2010),

129 however, these analyses have not been in the context of winter, nor have they synthesised across

130 diverse taxa and abiotic drivers. Thus, we need a framework to identify climate-change-

131 susceptibility that explicitly includes winter processes and incorporates evolution, ecology and

132 physiology. An essential starting point is a synthesis of the mechanistic bases for the complex responses to interacting winter climate drivers across terrestrial taxa.

Here we present a multi-component framework for predicting the impact of change in 135 abiotic winter drivers on a terrestrial organism. We begin by describing the predicted changes in 136 winter climate, then synthesise the mechanistic bases for the biological impacts of winter climate 137 change across terrestrial taxa and regions. We use this synthesis to identify key traits that make 138 species susceptible to changing winter conditions, and integrate the current state of knowledge 139 on impacts of winter climate change within the body of knowledge of growing season processes.

140 We focus on traits influencing exposure and sensitivity to a particular stress, which may arise from a number of drivers or interactions between drivers, and through both biotic and abiotic 142 processes. Our review is not meant to be exhaustive in scope, but rather to draw on 143 representative examples across taxa to illustrate the main biological impacts of winter across a 144 range of terrestrial organisms, to provide a starting point for readers to access the literature 145 relevant to their system, and to guide future research in the field of winter-focused global change 146 biology. This framework is designed to provide researchers with the means to navigate from 147 change in a climate driver to a list of potential biological impacts an organism may experience, 148 and to make a qualitative assessment of the likelihood of any terrestrial organism to suffer a 149 given biological impact. 


\section{Winter climate change}

Mean winter air temperatures are increasing globally, but the magnitude of

153 predicted winter climate change varies by region (Figure 1A; IPCC, 2007), and is subject to

154 complex feedback mechanisms and interactions between snow- and ice-cover and temperature.

155 While increased temperature alone decreases snow cover, climate models predict that winter 156 precipitation may increase, decrease or change in timing or duration depending on the region 157 (Figure 1B), which means that snow depth may stay the same or even increase in some regions, 158 such as parts of the Arctic (Symon, Arris \& Heal, 2005). Many organisms overwinter beneath 159 snow, and snow cover is a critical mediator of soil microclimate; in particular, both reduced 160 precipitation and increased mean air temperatures can increase the frequency and intensity of soil 161 freeze-thaw cycles (Figures 2B, D; Brown \& DeGaetano, 2011). Although the Arctic is predicted 162 to experience the most extreme winter warming, changes in snow cover and soil freezing in this 163 region are less sensitive to warming than in northern temperate regions, which feature a shallower snowpack and remain closer to melt temperatures over winter (Henry, 2008). The 165 changing physical conditions of winter can also modify winter length; for example, 'vanishing 166 winters' are predicted for low-latitude temperate regions, where persistent snow cover and soil 167 freezing become rare or completely absent (Kreyling \& Henry, 2011), and the 'average' winter 168 may be getting shorter in temperate North America, where the first autumn frost has been getting 169 later, and the last spring frost earlier, for several decades (Kunkel et al., 2004).

171 [Figure 1 here] 
In addition to changes in mean temperature and precipitation, an increased frequency of

174 extreme weather events can increase the incidence, frequency and intensity of soil freezing,

175 either as a result of unusually early or late winter frost events, or as a result of mid-winter

176 warming (or rain) events that reduce snow cover and are followed by freezing temperatures

177 (Figure 2C). There has been an overall increase in the frequency of extreme thermal events in

178 both summer and winter, and further increases are predicted over the next century (Easterling et

179 al., 2000). Increases in extreme minimum and maximum temperatures in recent decades have

180 varied among seasons and among regions, but overall there has been an increased number of

181 days of extreme high minimum temperature and a reduced number of days of extreme low

182 minimum temperature (Caprio, Quamme \& Redmond, 2009; Easterling et al., 2000). For

183 example, across Canada the number of cold nights (minimum temperatures below the $10^{\text {th }}$

184 percentile for the $20^{\text {th }}$ century) decreased by 15 per year between 1950 and 2003 (Vincent \&

185 Mekis, 2006). The frequency of both extreme high temperatures and longer mid-winter warm

186 spells is expected to increase with climate change in some regions (Liu et al., 2006).

187

188 [Figure 2 here]

189

Aside from thermal stress, interactions between temperature and moisture during winter

191 can alter the occurrence of physical stresses such as ice encasement and frost heave (the uplift of

192 soil when freezing water in soil expands), and increased rainfall over winter will increase the

193 frequency of rain-on-snow events, which contribute to ice encasement. Rain-on-snow events

194 have increased in most Arctic regions, in some cases by up to 50\% (ACIA, 2005). Furthermore,

195 changes in albedo and permafrost depth can modify water retention by the soil, which can alter 
196 the nature of below-ground freeze-thaw (Oztas \& Fayetorbay, 2003). Changes in sea or lake ice

197 can also exacerbate terrestrial climate change, for example by increasing moisture availability,

198 leading to increased snow depth in maritime areas, or by modifying albedo and accelerating

199 spring melt (Deser et al., 2010). With the emphasis on temperature effects in winter research,

200 such interactions with moisture have often been overlooked, and consequently our discussion of

201 these specific moisture effects remains speculative (and is often absent) throughout much of this

202 review.

203

204 III. Mechanistic bases of the biological impacts of winter climate change

205 The primary abiotic drivers of the biological impacts of winter on terrestrial systems are 206 temperature and snow cover. Temperature determines rates of biological processes, and thermal 207 variability impacts the likelihood of crossing important biological thresholds (e.g. the freezing 208 point of tissues). Snow strongly modifies both the physical and the thermal environments.

209 Changes in the absolute variability of these factors (as well as their timing and synchrony) can 210 modify the interaction and outcomes of snow cover and temperature. In Figure 3, we describe 211 how these drivers interact to determine biological impacts, and we show the direction of impact 212 of changes in some of these drivers (which we elaborate below). Ultimately, the susceptibility of 213 organisms to winter (see Table 1 for a description of the traits influencing vulnerability to winter 214 changes), and the way these impacts combine and synergise with impacts of climate change 215 during the growing season will determine the winners and losers under global climate change, 216 and understanding these processes will be essential for informed management of biodiversity in a 217 changing world. 
219 [Figure 3 here]

220

221 [Table 1 here]

222

223 (1) Increased average winter temperatures

224 (a) Effects on metabolic rate

225

Increased average temperatures can arise either as a direct result of climate warming, for 226 organisms whose habitats are not buffered from ambient temperatures, or from increased snow

227 cover with associated thermal buffering (Figures 2A-B, Figure 3). Increased average

228 temperatures can impact energy stress and phenology by increasing rates of development or 229 metabolism (Figure 3). Temperature influences metabolism, and thus consumption of stored 230 energy by 1) directly determining the rates of metabolic processes (such as respiration and 231 carbon fixation) in poikilotherms and 2) determining the costs of thermoregulation by 232 homeotherms. Thus, increased average temperatures will increase rates of metabolism of 233 poikilotherms, while for homeotherms below the thermoneutral zone, metabolic rates will 234 decrease with increased average temperature due to the decreased cost of thermoregulation 235 (Table 1).

236 A higher metabolic rate will increase the rate of use of stored energy reserves, which can 237 expose non-feeding organisms to energetic stress (Figure 3). For example, hibernating bats 238 expend more energy when hibernaculum temperatures are above an optimal low temperature 239 (Humphries et al., 2002), dormant hatchling turtles consume more energetic reserves and emerge 240 in poorer physiological condition after warm winters (Muir et al., 2013), and energy drain means 241 that goldenrod gall flies that overwinter in relatively warm subnivean microclimates have 
242 reduced survival and fecundity compared to conspecifics overwintering in exposed, colder sites,

243 because their metabolic rates increase exponentially with temperature (Irwin \& Lee, 2003). All

244 else being equal, this energy drain is likely to be more pronounced in organisms with high

245 baseline metabolic costs, and less pronounced in organisms, such as diapausing butterfly pupae,

246 that substantially suppress their metabolism during winter (Table 1; e.g. Williams, Hellmann \&

247 Sinclair, 2012a).

248 Increased rates of biological processes may permit energy gain for organisms that can

249 take up nutrients during the winter. For example, increased winter temperatures increase

250 photosynthetic rates and thus carbon gain in non-dormant plants as long as water is available,

251 although this effect is more pronounced in woody than in herbaceous species (Ensminger, Busch

252 \& Hüner, 2006). Similarly, the mineralization of limiting nutrients such as nitrogen increases

253 with soil temperature over winter (Sturm et al., 2005), which can increase primary productivity,

254 assuming that nutrient release and uptake are synchronised (Groffman et al., 2001).

255 For homeotherms, the energetic costs of thermoregulation during winter can rival or

256 exceed energetic costs of the breeding season, yet occur at a time when food availability may be

257 low (Sgueo et al., 2012). An increase in average winter temperatures will thus lower metabolic

258 costs of thermoregulation in homeotherms that would normally experience winter temperatures

259 below the thermoneutral zone, which may alleviate energetic stress (Figure 3; Sears et al., 2009).

260 A release from energetic stress as a result of winter climate change may have led to recent

261 increases in body size of American martens, either via decreased thermoregulatory costs or

262 increased prey availability (which will reduce energetic stress by increasing nutrient uptake;

263 Yom-Tov, Yom-Tov \& Jarrell, 2008). Increased body size and/or condition will likely translate

264 into fitness benefits by decreasing overwinter mortality (Hodges et al., 2006), or improving 
265 condition at the onset of the breeding season (e.g. Guillemain et al., 2008). Alternately,

266 decreased thermoregulatory costs may increase fitness by reducing the need for pre-winter

267 energy accumulation, which could mitigate trade-offs and predation risk associated with resource

268 acquisition (Gentle \& Gosler, 2001). By contrast, warmer winters may lead to summer energy

269 drain for species such as polar bears that feed primarily during winter and fast in the summer.

270 Warmer winters reduce the length of sea ice stability, resulting in a shorter period in which polar

271 bears can acquire their year's nutrients, offsetting any thermoregulatory benefits (Robbins et al., 272 2012).

273 However, direct evidence for energetic and performance consequences of winter

274 warming in homeotherms is scarce. Changes in variables correlated with increased temperatures

275 - such as snow cover, resource availability, and precipitation - make it difficult to isolate the

276 impacts of temperature in observational studies, which form the majority of published work to

277 date. For example, although they presumably provide a thermoregulatory advantage, warm

278 winters reduced maternal investment in reproduction in red deer resulting in smaller offspring.

279 This effect was probably driven by increased costs of locomotion in the deeper snow

280 characteristic of warm winters, rather than increased temperature per se (Post et al., 1997). Thus,

281 the impact in this case was driven by an interaction among abiotic drivers (Figure 3).

282 (b) Effects on development and phenology

283 In addition to altering energy balance, increased average temperatures during winter

284 generally promote development at times of year when it would traditionally be arrested, leading

285 to earlier spring, and later autumn, phenology for the majority of terrestrial taxa (Figure 3; Jeong

286 et al., 2011; Walther, 2010). These phenological shifts have been particularly pronounced in cold

287 regions such as the Arctic (Høye et al., 2007). However, significant variation exists in 
288 phenological plasticity within communities; for example, phenological shifts have been faster at 289 lower trophic levels (Table 1; Both et al., 2009; Thackeray et al., 2010), and within the insects, 290 these shifts are less pronounced in species with specialised diets or that overwinter at earlier life 291 stages (Table 1; Diamond et al., 2011).

292 For primary producers, or animals that are not limited by resource availability, 293 performance is likely to be enhanced by maximally-advanced spring phenology and maximally294 delayed autumn phenology (Table 1). Shortening the period of dormancy will allow greater 295 resource accumulation during the growing season, and less energetic stress during winter. If this 296 hypothesis is correct, performance will be enhanced in organisms whose phenology is strongly 297 temperature-sensitive and which can therefore respond to increases in average temperatures by 298 rapid shifts in their growing season. Indeed, the ability to respond to climate change by 299 advancing spring phenology strongly enhances fitness and persistence in plants (e.g. Fridley, 300 2012), presumably by lengthening the growing season and increasing resource accumulation 301 (Pigliucci \& Marlow, 2001). A recent evolutionary shift towards later autumn phenology has 302 also been recorded in pitcher plant mosquitoes, implying fitness gains from an extension of the 303 length of the growing season (Bradshaw \& Holzapfel, 2001), perhaps because resources are not 304 temporally limited for mosquito larvae feeding on microbes in the contained pitcher plant 305 ecosystem.

By contrast, phenological synchrony with crucial resources will likely be more important 307 than growing season or winter length in determining fitness of organisms at higher trophic levels 308 whose resources are temporally limited. This means that the optimal phenotype will depend on 309 the phenology of the neighbouring trophic levels (Table 1). This dependence occurs because 310 variation in phenological shifts can cause community mismatches, wherein resources for higher 
311 trophic levels are no longer synchronised with periods of demand. We will discuss the

312 community-level implications in more detail below (section V), but the salient point at the 313 organismal level is that a mismatch between food demand and availability is likely to apply 314 strong selective pressure on higher trophic levels to maintain synchrony with the trophic levels 315 below. Supporting the hypothesis that phenology may evolve to enhance synchrony with the 316 trophic level below, winter moth caterpillars have evolved a later spring hatching date in 317 response to warming, which has increased synchrony with budburst of its host plant (oak), and 318 presumably imparted higher fitness despite a shorter growing season (van Asch et al., 2013). 319 Thus, the pattern of selection on phenology likely differs among trophic levels, with 320 producers or animals for which resources are available year-round experiencing consistent 321 selection for maximal spring advances and autumn delays, while higher trophic levels experience 322 divergent selection pressures that depend on the responses of the trophic level immediately 323 below. This differential selection across trophic levels could explain why the responses of plant 324 phenology to climate change show a strong phylogenetic signal (Willis et al., 2008), while the responses of insect phenology do not (Diamond et al., 2011): consistent selection on phenology 326 in producers preserves the phylogenetic signal, while divergent selection on phenology at higher 327 trophic levels reduces similarities across the phylogeny. Therefore, although it is likely that 328 phenological shifts will alter resource availability and thus energy stress for consumers whose 329 resources are temporally restricted, determining whether the impact will be positive or negative 330 requires consideration of the phenological responses of organisms at lower trophic levels (Figure 3313 , Table 1). Organisms for which seasonal timing is physiologically fixed, and that therefore 332 have inflexible phenology, may suffer the most pronounced negative impacts of changing winter 333 length and timing with climate change (Post \& Forchhammer, 2008). 
Many plants and insects have chilling or vernalisation thresholds that must be met before

335 post-winter development can resume. In these cases, warmer winters can slow development,

336 leading to phenological delays (rather than advancement) in spring (e.g. Forrest \& Thomson,

337 2011; Luedeling et al., 2011). Most studies report an advance in spring phenology, although

338 these are also intermixed with delays or lack of responses in many systems (Thackeray et al.,

339 2010); these delays are consistent with widespread effects of a reduction in chilling units (Cook

340 et al., 2012). Phenological delays have been well-documented in meadow and steppe plant

341 communities on the Tibetan Plateau, where the beginning of the growing season advanced in

342 response to climate warming for the first half of a 20-year warming period, but was subsequently

343 delayed despite continued climate warming (Yu, Luedeling \& Xu, 2010; but see Zhang et al.,

344 2013). These phenological delays are consistent with insufficient vernalisation (too little

345 accumulated cold exposure to end dormancy). However, these observations could also arise

346 from the observed decrease in snow depth over this period, which may have reduced the

347 insulation of the roots and, counter-intuitively, resulted in colder conditions despite warming air

348 temperatures (Yu et al., 2013). There is no way to separate these proximal mechanisms from the

349 available data, although this could be achieved through either autecological experiments on

350 chilling requirements (e.g. Santiago et al., 2013) or experimental snow manipulation (e.g.

351 Groffman et al., 2001).

352 Average temperatures will thus affect energy balance in two ways - directly, through

353 rates of metabolism, and indirectly, through phenology and the resulting length of winter (Figure

354 3). This introduces an important dichotomy in responses to winter climate change among

355 dormant plants and insects: for cold-adapted species with high chilling or vernalisation

356 requirements, increases in winter temperature will increase both overwinter energy use (by 
357 increasing metabolic rates) and winter length (by increasing development time). These changes

358 will amplify the deleterious effects of warming for cold-adapted species. If failure to meet

359 chilling requirements decreases the viability of populations, it may prove to be a proximate

360 driver of range contractions at the equatorial range limit in some species. By contrast, for warm-

361 adapted species that do not have chilling or vernalisation requirements, although warming will

362 still increase overwinter energy use, it will also shorten the period of dormancy by advancing

363 spring phenology. This could mitigate the direct negative effects of winter warming on

364 energetics of warm-adapted species.

366 (2) Altered thermal variability

367 Winter temperatures fluctuate on multiple temporal scales, ranging from diel temperature

368 fluctuations, through short term cycles associated with weather fronts, to seasonal changes

369 (Deere \& Chown, 2006; Gaines \& Denny, 1993; Marshall \& Sinclair, 2012a; Marshall \&

370 Sinclair, 2012b). The magnitude of these fluctuations varies spatially both with microhabitat

371 (Marshall \& Sinclair, 2012b), and across larger scales influenced by continentality, latitude and

372 topography. Snow cover will drive much of this variability, so snow cover predictions must be

373 taken into account to determine likely trends in variability in each of these components (Figure

374 2). Changes in the seasonal timing of snow cover will exacerbate altered timing of extreme low

375 temperatures (Figure 2). Changes in thermal variability will impact energy balance, phenology,

376 and cold injury through effects on metabolism, development, and freeze/thaw cycles as described

377 below (Figure 3). Species-specific sensitivity to changes in this variability may be particularly

378 important in determining organisms' responses to winter climate change, although we note that

379 changes in variability are extremely difficult to predict, even when only extreme events are 
380 considered (Easterling et al., 2000). There are three salient components of fluctuations in winter 381 thermal conditions: a) the intensity and regularity of extreme high and low winter temperatures;

382 b) the frequency with which temperatures cross important physical thresholds (e.g. the freezing 383 point of water) or biological thresholds (e.g. thresholds for cold-induced damage); and c) the 384 amplitude of thermal cycles on both diel and short-term scales (such as during storm events).

(a) Intensity and regularity of winter extremes

Extreme low temperature events can cause cold injury, and winter mortality or injury is 387 an important component of demographics for many species (e.g. Aukema et al., 2008; Kanda, 388 2005; Spiegel-Roy \& Goldschmidt, 2008; Sutherst \& Maywald, 2005). Thus, a reduction in the 389 intensity or duration of extreme winter low temperatures could increase winter and post-winter 390 survivorship (Table 1; e.g. Tran et al., 2007; Trotter \& Shields, 2009), directly influencing the 391 poleward or upper altitudinal range limit of a species (e.g. Crozier, 2004; Neuvonen, Niemelä \& 392 Virtanen, 1999). However, there are cases where extreme low temperatures do not directly limit 393 population persistence or geographic range. For example, the monophagous holly-leaf miner (an 394 agromyzid fly) is more cold tolerant than its host plant (holly, Ilex aquifolium), and its northern 395 range limit in Europe is therefore likely set by the factors that set the host range, rather than 396 directly by extreme low temperatures (Klok, Chown \& Gaston, 2003). In such cases, 397 amelioration of extreme low temperatures will not directly affect survival, but could still 398 indirectly lead to range expansion if low temperatures are the primary determinant of resource 399 availability.

400 Changes in thermal variability can modify the timing, predictability and sequence of 401 extreme events over winter. Because many species have life stage-specific tolerance to winter 402 conditions (e.g. diapause-linked cold tolerance in insects, Leather, Walters \& Bale, 1993; and 
403 aquatic overwintering in adult frogs, Tattersall \& Ultsch, 2008), there is potential for changes in 404 the seasonality of extremes to lead to mismatches between the occurrence of extreme events and 405 the behavioural or physiological mechanisms that allow organisms to tolerate them. In 406 particular, organisms with seasonally-programmed responses, or those which irreversibly lose 407 cold tolerance during winter warm spells, will be more vulnerable to unseasonable temperature 408 extremes than those with constitutively high or rapidly-modified tolerances (Table 1). For 409 example, extremely warm mid-winter temperatures cause an irreversible loss of winter 410 acclimatisation and the resumption of development in the emerald ash borer (Agrilus 411 planipennis, Coleoptera, Buprestidae), making them susceptible to subsequent cold snaps 412 (Sobek-Swant et al., 2012). Extreme warm periods in spring can also lead to breaking of 413 dormancy in plants, with subsequent extreme events killing buds and preventing reproduction or 414 growth the following season, as occurred in the unusual North American springs of 2007 415 (Augspurger, 2009; Gu et al., 2008) and 2010 (Hufkens et al., 2012). Indeed, a 124-year 416 temperature dataset combined with observations of frost susceptibility in Illinois, USA shows 417 that the frequency of damaging spring frost events has increased in recent decades (Augspurger, 418 2013). At the beginning of winter, unusual extreme events before organisms have accumulated 419 programmed physiological protection can also lead to damage. For example, the grass Bromus 420 rubens may be excluded from the intermountain steppe biome of western North America as a 421 consequence of sudden freeze events in late autumn before the onset of (programmed) winter 422 cold tolerance (Bykova \& Sage, 2012). Thus, organisms that develop low temperature tolerance 423 in a programmed fashion (e.g. in response to photoperiod), or that have delayed the onset of 424 winter hardening as part of a phenological shift, may be more vulnerable to changes in the 
425 occurrence of extreme events in autumn than organisms that can use temperature as a cue to 426 rapidly increase early winter cold hardiness (Table 1).

427 (b) Frequency of threshold-crossing events

428 Changes in the frequency, intensity, or duration of extreme events could modify the 429 frequency with which biologically-important thresholds are crossed. For example, the $0{ }^{\circ} \mathrm{C}$ 430 threshold delineates the availability of liquid water and the beginning of soil freezing. Similarly, 431 species-specific physiological thresholds exist, such as the temperatures at which ice formation 432 and melting occur; crossing these thresholds can determine sub-lethal impacts (e.g. Marshall \& 433 Sinclair, 2010), survival (e.g. Régnière \& Bentz, 2007) and overwinter energetics (e.g. Sinclair et 434 al., 2013) In some regions (e.g. maritime-buffered habitats in the southern hemisphere; Chown 435 et al., 2004), temperatures already hover near the $0{ }^{\circ} \mathrm{C}$ threshold: increases in mean temperatures 436 will likely reduce the occurrence of freeze-thaw cycles in such environments, reducing the stress 437 of threshold-crossing events. By contrast, increasing mean temperatures (or decreasing snow 438 cover, see below) may increase the incidence of freeze-thaw in northern temperate habitats, and thus may increase the frequency of such transitions.

440 The implications of repeated freeze-thaw are not well-understood, but the impacts appear 441 to be largely negative. In invertebrates, repeated freeze-thaw can lead to a variety of deleterious 442 consequences, due to both cold injury from the repeated cold exposure, and increased energy 443 expenditure during repair and recovery in thaw periods (Marshall \& Sinclair, 2012a). In freeze444 tolerant Rana sylvatica frogs, carbohydrate energy reserves provide both fuel for the energy 445 expended during freezing and the cryoprotectants for survival of freezing itself. In this species, 446 repeated freeze-thaw both depletes energy reserves and reduces cold tolerance, suggesting the 447 possibility for substantial fitness reductions with increased freeze-thaw (Sinclair et al., 2013). 
448 Repeated freeze-thaw cycles increase the risk of xylem embolism in conifers due to the 449 expansion of gas bubbles during thawing that were formed upon freezing (Mayr, Gruber \& 450 Bauer, 2003). Increased intensity or frequency of soil freeze-thaw cycles can increase the lysis of 451 soil microorganisms and damage to plant roots, intensifying leaching and trace gas losses of soil 452 nutrients (Groffman et al., 2001).

453 In some cases, the impacts of repeated events such as freezing may not be cumulative.

454 For example, elevated losses of soil nutrients may only occur in response to exceptionally severe 455 frost soil events, and pools of frost-vulnerable materials in the soil are finite. Once the bulk of 456 soil nutrients in these frost-vulnerable pools have been released, subsequent events may not 457 result in further loss (Matzner \& Borken, 2008). Thus, increased frequency of freeze-thaw can 458 have detrimental effects in organisms for which the responses are cumulative, but for organisms 459 or systems where the impact of repeated cold exposure reaches an asymptote (e.g. nutrient 460 leaching), the impacts of repeated events may be less important (Table 1). However, at this point 461 too little is known about the impacts of repeated stress (or about interactions among multiple 462 stressors) to allow generalities to be constructed.

463 (c) Impacts of the amplitude of thermal cycles

464 Increases in daily thermal variability can increase rates of metabolism and photosynthesis 465 in poikilotherms (Figure 3), because of the curvilinear relationship between temperature and 466 most biological rate processes. Jensen's inequality is a mathematical property of nonlinear 467 functions, which states that the mean of a nonlinear response variable cannot be predicted based 468 on the mean of the driver variable alone, but requires knowledge of the variability of the driver 469 variable and the shape of the response function (Ruel \& Ayres, 1999). For example, if the 470 response function is accelerating over the range of temperature fluctuations (as is frequently the 
471 case with metabolic rate in ectotherms), the mean of the response variable will be elevated

472 compared to its value at the mean temperature, and increasing thermal variability will further

473 increase the mean of the response variable, even without a corresponding increase in the mean

474 temperature. Thus, increases in thermal variability have the potential to exacerbate the impacts of

475 an increase in mean temperature on metabolism (Ruel \& Ayres, 1999). Additionally, thermal

476 performance curves are asymmetric (fitness rapidly declines above the thermal optimum;

477 Angilletta, 2009), and thus Jensen's inequality means that the impact of changes in temperature

478 will also be asymmetric: temperatures above the thermal optimum will reduce fitness far more

479 than temperatures an equal amount below the thermal optimum.

480 This effect of Jensen's inequality can be exacerbated or mitigated by modifying the shape

481 of the rate-temperature relationship: a steeper curve (i.e. higher temperature sensitivity) will lead

482 to a more pronounced impact (Ruel \& Ayres, 1999), suggesting that organisms with high

483 temperature sensitivity or thermal optima that are close to environmental temperatures will

484 experience greater impacts of changes in thermal variability (Table 1; Foden et al., 2013).

485 Exacerbated thermal variability will therefore allow potentially-active ectotherms to take better

486 advantage of warm spells during winter fluctuations. However, lower thermal sensitivity will

487 reduce vulnerability to thermal variation, for example in energy-conserving overwintering

488 ectotherms (Williams et al., 2012b). Thus, short-term (e.g. daily) thermal variability likely

489 exerts a strong selective pressure on temperature-rate relationships in ectotherms and plants,

490 however, few studies to date have examined the impacts of daily thermal variability on

491 overwintering organisms.

492 For dormant organisms, thermal variability will thus be an important determinant of

493 overwintering energy use, particularly at winter's peripheries when temperatures are relatively 
494 warm and variable. In this context, seasonal timing will be a critical determinant of a species’

495 susceptibility to overwinter energy drain resulting from alterations to thermal variability.

496 Species that enter dormancy early in the autumn will experience significant energy drain as a

497 result of delayed winter onset, and an increase in thermal variability during autumn will thus

498 exacerbate this energy drain because of Jensen's inequality (e.g. Sinclair et al., 2013; Williams et

499 al., 2012b). By contrast, species with delayed spring emergence, including insects such as

500 Rhagoletis pomonella that infest summer-fruiting trees (Feder, Hunt \& Bush, 1993), will likely

501 be more susceptible to earlier, more variable, and warmer springs. By contrast, increased

502 buffering (e.g. due to longer snowpack persistence; Decker et al., 2003) might reduce variability,

503 mitigating the impact of the longer post-winter period.

504 Flexibility of the thermal sensitivity of biological processes or phenology will therefore

505 be a key determinant of the outcome of changing thermal variability during winter and its

506 associated dormancy (Figure 4). Suppression of thermal sensitivity of metabolism mitigates the

507 impact of increased thermal variability (Williams et al., 2012b). In herbivores, for which entry

508 into dormancy is likely mediated by a decline in host plant quality (Prior et al., 2009), such

509 plasticity is essential, but may not fully compensate for increased autumn variability (Williams et

510 al., 2012b). In many species, the onset of dormancy is controlled hormonally and entrained to

511 photoperiod (Tauber et al., 1986), apparently reducing the capacity for flexibility because of the

512 programmed nature of the response. However, evolutionary changes in the induction of

513 dormancy as a result of climate change have been observed in a photoperiod-cued pitcher plant

514 mosquito (Bradshaw \& Holzapfel, 2001). Similarly, butterfly larvae show state-dependent

515 responses to photoperiod, allowing facultative shifts in dormancy onset and behaviour both

516 before and after dormancy to buffer the impact of reduced growth capacity at higher latitudes 
517 (Gotthard, Nylin \& Wiklund, 1999; Gotthard, Nylin \& Wiklund, 2000). It is conceivable that 518 such plasticity could also act to mitigate the impacts of winter energy drain.

[Figure 4 here]

521

Overall, while it is clear that the frequency, timing and amplitude of temperature variability dictate the severity of winter's effects on organisms, the examples presented above

524 derive primarily from studies on insects. For organisms with more resilient or resistant

525 overwintering stages (e.g. plant seeds) these effects may be less severe. The ultimate influence

526 of extreme winter temperature events on populations, communities and ecosystems will be a

527 function of both the severity and frequency of these events, and extremely severe events may

528 only occur infrequently. However, extreme events that lead to threshold changes in community

529 trajectories will remain influential over the longer term (Kreyling, Jentsch \& Beierkuhnlein, 530 2011).

531

532 (3) Changing snow cover

533 The strong influence of snow cover on the soil and subnivean microclimate (Figure 2;

534 Decker et al., 2003; Henry, 2008; Pauli et al., 2013) has important consequences for the 535 condition and survival of organisms that overwinter in these environments, and as a result, 536 changes in snow cover with climate change can result in many different biological impacts

537 (summarised in Table 2). Because snow is an effective insulator, reduced snow cover can 538 expose soil systems to more extreme low temperatures (Brown \& DeGaetano, 2011), described 539 by Groffman et al. (2001) as 'colder soils in a warmer world', which in turn can increase 
540 mortality for organisms overwintering in or on the soil. Beetles overwintering in the soil beneath

541 snow in the US prairies had higher survival than those that overwintered in soil with snow

542 removed, but this difference in survival was only seen in relatively cold winters (Joshi, Olson \&

543 Carey, 2009), and the number of times per month that New Zealand alpine cockroaches were

544 predicted to freeze and thaw ranged from zero to more than 20, depending on snow cover

545 (Sinclair, 2001). Lemming nest density was positively correlated with snow depth when snow

546 cover was experimentally manipulated, presumably because the deep, dry snow layer buffered

547 the small mammals from extreme temperatures (Reid et al., 2012).

548

549 [Table 2 here]

550

551

Thermal buffering by snow leads to a counterintuitive observation - organisms from very

552 cold and snowy regions are frequently less cold tolerant than those from regions with a shallower

553 and less-persistent snow-pack. For example, despite the expectation that frost tolerance increases

554 with increasing latitude within species, northern (snow-insulated) ecotypes of temperate grasses

555 have low frost tolerance relative to their conspecific, southern ecotypes that experience less snow

556 cover (Dionne et al., 2001). Increased soil freezing as a consequence of decreased snow cover

557 might therefore be particularly damaging for organisms adapted to snowy winters. Mid-winter

558 melts can increase soil exposure to freeze-thaw with consequent damage to plants and soil fauna

559 (Bokhorst et al., 2011; Bokhorst et al., 2012a), and these melts also can lead to ice encasement

560 and subsequent anoxia, further stressing soil organisms (Coulson et al., 2000). Despite the

561 potential benefits of snow cover for frost protection, the mild subnivean microclimate can be

562 energetically costly for organisms, because overwinter temperatures determines their energy 
563 consumption (Figure 3). For example, gall flies overwintering below the snow have increased 564 energy consumption compared to those above the snow (Irwin \& Lee, 2003). Snow cover thus 565 strongly influences levels of energy stress and cold injury indirectly, through its effects on 566 temperature (Figure 3), and changes in local patterns of snow cover therefore have the potential 567 to alter habitat suitability on a very small scale.

568 Snow also impacts organisms directly by modifying the physical environment: both the 569 quantity and the quality of snow can have profound effects, particularly on the biology of winter570 active mammals. While the effects of changing snow cover can be assessed experimentally for 571 sessile or small organisms (e.g. Groffman et al., 2001; Reid et al., 2012), the limited spatial scale 572 of most snow manipulation experiments makes it difficult to assess snow depth effects on large 573 or highly mobile animals under controlled conditions. Nevertheless, observational studies can be 574 used to correlate biological responses to interannual variation in snow depth. For example, 575 wolves form larger packs in response to deeper snow (Post et al., 1999), but increased snow 576 depth also reduces mobility of their deer prey (Fuller, 1991). Reduced snow cover may also 577 increase resource availability for winter-active predators and browsers by improving access to 578 food (Figure 3; Martin \& Maron, 2012) - which necessarily means that decreased snow also 579 increases predation risk for small mammals which have less protection from predators and 580 extreme temperatures (Yoccoz \& Ims, 1999). However, the impacts of changing snow cover are 581 complex: declining snow cover in Canada is associated with decreased wolverine population 582 growth rate; the causal factors for this decline likely include reduced denning sites, decreased 583 prey success and reduced snow-related mortality of the ungulates upon whose carcasses 584 wolverines scavenge (Brodie \& Post, 2010). Snow quality, determined more-or-less directly by 585 temperature, also determines the winter performance of many organisms, as changes in the 
586 density of snow modifies its insulative properties and affect locomotion, while ice layers can 587 modify access through the snowpack. For example, increased frequency of rain on snow events, 588 and subsequent ice-up, blocks access to food for herbivores such as reindeer (Hansen et al., 589 2011) and small mammals (Kausrud et al., 2008; Korslund \& Steen, 2006).

590 The timing of snow lie is also critical for many organisms, but the direction of impact 591 strongly depends on species' traits. Early snowmelt can have positive effects for large browsers 592 such as reindeer, which produce calves with increased body mass in the autumn following an 593 early spring snowmelt (Pettorelli et al., 2005). However, if early snow melt causes the 594 resumption of activity before resources are available or interrupts winter feeding opportunities, 595 the effects can be detrimental: early snowmelt can result in food scarcity for hibernating 596 mammals, such as marmots, that emerge early in response to warmer air temperatures, but before 597 the spring flush of plant growth (Inouye et al., 2000), and early ice breakup increases mortality in 598 polar bear by reducing the length of the winter feeding season and increasing the length of the 599 summer fast (Regehr et al., 2007). By contrast, increased spring snowstorm activity with climate 600 change in some regions can lead to delayed snowmelt, delaying the emergence of ground 601 squirrels and reducing their fitness by reducing the length of the active season (Lane et al., 602 2012). However, organisms that overwinter in subnivean spaces in very cold environments may 603 benefit from an extension to the protective insulation of snow - for example, peak floral 604 abundance of montane plants is increased after delayed snow melt, due to decreased frost 605 damage in spring (Inouye, 2008).

Mid-winter snowmelt caused by extreme events (best-studied because of their effect on 607 hydrology; e.g. Kurian, Lautz \& Mitchell, 2013) will not only affect overwinter soil temperatures 608 (see above), but also provide liquid water for plants and animals that might otherwise suffer from 
609 a water deficit, such as hibernating mammals (e.g. Ben-Hamo et al., 2013). Conversely,

610 increased free water may increase rates of heat loss and risk of flooding, decreasing survival of

611 small mammals (Kausrud et al., 2008). In Greenland, warmer summers result in the

612 accumulation of cold meltwater, delaying flowering and shortening the flowering period of

613 several angiosperms (Høye et al., 2013). These roles of liquid water in determining winter

614 physiology and spring phenology in terrestrial systems during winter have received little

615 attention, so the trade-off of negative and positive effects for organisms remains a matter for

616 speculation.

617

618

619

IV. Links between winter and summer responses to climate change

The condition of organisms emerging from the winter will determine their performance

620 during the growing season, and similarly their growing season performance will determine their

621 condition going into the winter and subsequent winter performance (Figure 5). Taking a cross-

622 seasonal perspective will therefore be necessary to identify negative impacts of climate change.

623 For example, advanced spring phenology and increased spring abundance of a perennial herb in

624 Britain resulted from winter warming, but this was tempered by a decrease in reproductive

625 output by those plants (Fox et al., 1999). Similarly, early snow melt increased survival in

626 conifers, but at the expense of growth rates (Barbeito et al., 2012). Where data on post-winter

627 performance are lacking, links from winter condition to the growing season may often be

628 inferred. For example, winter energy use can determine adult body size in butterflies (Williams

629 et al., 2012a), and the clear size-fecundity relationship in female butterflies (Boggs \& Freeman,

630 2005) implies a fitness consequence of this winter effect. The resilience of organisms to winter

631 energetic stress can also be determined by post-winter processes (Table 1), with resilience

632 decreased in organisms with limited opportunities for post-winter resource acquisition (Breed, 
633 Stichter \& Crone, 2013), or for which juvenile-derived reserves are essential for reproduction 634 (Irwin \& Lee, 2003).

635

$636 \quad$ [Figure 5 here]

637

If responses to climate change improve pre-winter condition, winter performance may be 639 enhanced. For example sub-alpine yellow-bellied marmots have advanced their phenology in 640 response to recent climate change, which allows increased resource accumulation and growth 641 and, consequently, increased overwinter survival and population growth rates (Ozgul et al., 642 2010). Presumably, such positive impacts of longer growing seasons will help to buffer negative 643 impacts of winter climate change, although few data exist to address this hypothesis. However, 644 some changes to growing season physiology may have negative effects on winter performance. 645 For example, damselfly larvae that grow rapidly during the growing season do so at the expense 646 of winter cold tolerance (Stoks \& De Block, 2011), although this trade-off was not apparent in 647 butterflies (Karl et al., 2013), underlining the likelihood that the relationship between summer 648 and winter will be complex and species-specific.

In Figure 5, we conceptualise the potential biological impacts of winter climate change 650 on a species in an inter-seasonal context. We assume that reproduction and growth occur outside 651 of winter - modification will be necessary for species that reproduce in winter. In Figure 5, the 652 winter variables that affect an organism are represented by 'Winter', while 'Mortality', 653 'Resources' and 'Sub-lethal damage' represent the outcomes of the biological processes and 654 stresses in Figure 3. Figure 5 can be used in two ways. First, it can be used in conjunction with 655 our framework describing the impacts of winter on a species' biology (Figure 3, Table 1) to 
656 identify areas in which further research is required. Second, by determining the causal links and

657 strengths of the relationships shown, it can be used to determine the relative importance of

658 different aspects of winter in determining how a species' vulnerability to overwinter conditions

659 plays out in the growing season and affects fitness.

660 The relationships between post-winter condition, growing season performance (and

661 reproduction) and pre-winter condition are already known for many species, thanks to the

662 preponderance of growing-season studies. Winter mortality has been well-explored for many

663 species (Aars \& Ims, 2002; Hodges et al., 2006; Roland \& Matter, 2013; Stahl et al., 2006), but

664 data are lacking regarding the sub-lethal impacts of winter, mediated through resource

665 consumption and damage, and the effects of these sub-lethal impacts on growing season

666 performance. Moving forward, the direct relationships between winter conditions and growing

667 season performance need to be explored further across many taxa (see Kreyling (2010) for a

668 plant-focused discussion of this point), as does the extent to which vulnerability to summer

669 changes may exacerbate or negate vulnerability to winter changes.

670

671 V. Scaling up to populations, communities, and ecosystems

672 The direct effects of winter climate change on individual organisms will combine and

673 synergise with competitive interactions to influence demography. Positive impacts of winter

674 climate change, in the form of decreases in winter mortality, may be balanced or cancelled out by

675 a corresponding increase in intra-specific competition. For example, early snow-melt and

676 increased availability of forage decreased overwinter mortality in reindeer, which increased

677 competition and slowed population growth (Tyler, Forchhammer \& Øritsland, 2008). Winter

678 climate change can affect population dynamics both directly and indirectly via different 
679 mechanisms. For example, in an alpine butterfly, delayed snow melt directly increased

680 population growth by increasing recruitment the subsequent year, and indirectly increased

681 population growth by increasing the peak abundance of the butterfly's floral resources (Boggs \& 682 Inouye, 2012). Climate change-related shifts in population densities and processes at the leading 683 and retracting range edges (Hill, Griffiths \& Thomas, 2011) lead to well-documented poleward 684 range shifts, especially in butterflies (Chen et al., 2011b; Hill et al., 2002; Parmesan et al., 1999). 685 In some cases, climate-driven range shifts have been directly attributed to changes in winter 686 climate (Berger et al., 2007; Crozier, 2004). Conversely, differential susceptibility to winter 687 climate change among populations could also reduce performance in peripheral populations 688 (Pelini et al., 2009), leading to range contractions in some species.

689 At community scales, complex multi-trophic interactions can drive the effects of climate 690 change on individual species. Alterations to the abundance of plants or animals as a result of 691 changes in mortality or phenology can be propagated through communities via consumer692 resource interactions. For example, in a deciduous forest, increased winter herbivory by elk as a 693 result of decreased snow cover depresses plant and associated bird communities throughout the 694 year (Martin \& Maron, 2012). A deeper snow pack in the Great Lakes region of the USA 695 increases hunting success of wolves leading to reduced moose populations, which releases fir 696 trees from heavy browsing and increases the fir understory (Post et al., 1999). In turn, these 697 changes in understory composition and browsing could depress soil respiration rates (Persson et 698 al., 2009). Community interactions can modify and even reverse the effects of climate change on 699 individual species. For example, winter-induced changes in herbivory can prevent shrub 700 expansion in Arctic tundra (Olofsson et al., 2009). In ecosystems where predator populations are 701 subject to bottom-up control due to resource limitation, negative effects of winter climate change 
702 on prey may extend to higher trophic levels. Winter climate change has decreased plant

703 production and forage quality, leading to declines in herbivore fitness (Awmack \& Leather,

704 2002; Bokhorst et al., 2012b), and the collapse of Arctic lemming population cycles has

705 decreased the population growth of several predator species (Gilg, Sittler \& Hanski, 2009;

706 Schmidt et al., 2012). Conversely, direct impacts of winter climate change on overwintering

707 carnivores may lessen predation pressure on prey species, with community-wide consequences

708 (Estes et al., 2011), although few examples of such climate-induced trophic cascades in a winter

709 context - perhaps because such studies have focused on Arctic and boreal habitats. These multi-

710 trophic interactions make it imperative to predict the direct impacts of winter climate change on

711 species that exert strong top-down or bottom-up control within their communities, perhaps aiding

712 to identify focal species for winter study.

713 As we have shown, winter affects different species in different ways. Thus, dissimilar

714 responses to winter climate change by different species can exacerbate phenological mismatches,

715 reconfiguring community interactions (Van der Putten, Macel \& Visser, 2010). For example,

716 winter climate change has led to earlier spring leaf-out and caterpillar emergence in European

717 oak forests, decreasing synchrony of (caterpillar) food supply with peak feeding times in

718 passerine birds (Both et al., 2009). Similarly, the plant growing season has advanced faster than

719 the timing of the caribou migration to Arctic breeding grounds, resulting in increasing calf

720 mortality and lower calf production (Post \& Forchhammer, 2008). By contrast, climate change

721 has actually improved host plant-herbivore synchrony in a sub-Arctic moth-birch system.

722 Previously, birch bud burst occurred too early for moth larvae to feed on young (palatable)

723 leaves. However, moth phenology has advanced more rapidly than birch in response to shorter

724 winters, which has improved synchrony and enabled moth larvae to exploit this new resource 
725 (Jepsen et al., 2011). In extreme cases such as irruptive outbreaks of the (winter-limited)

726 mountain pine beetle, winter climate change has contributed to altering landscape-level

727 processes: beetle infestation modifies tree survival and species composition, ultimately

728 converting forests in British Columbia from net carbon sinks to a source of carbon (Kurz et al., 729 2008).

730 The links addressed in Figure 5 can be extended to processes that occur at the community

731 or ecosystem scale. In doing so, additional links must be added to account for species

732 interactions such as competition, and ecosystem processes that determine seasonal changes in

733 resource availability. For example, Figure 6 (based on Sturm et al., 2005) describes potential

734 feedbacks between changes in snow cover, nutrient availability and plant species composition in

735 the Arctic. In this scenario, climate warming is expected to promote shrub expansion into

736 graminoid communities, increasing the trapping of snow. Increased depth and duration of the

737 snowpack can then increase nitrogen availability over winter by increasing soil microbial

738 activity, and because the shrub canopy is above the snow layer, bud-burst and photosynthesis can

739 occur earlier than in the low-statured graminoids, allowing the shrubs to access late-winter

740 nitrogen pulses. Decreased nitrogen availability over summer, enhanced by increases in low

741 quality, woody shrub litter, coupled with increased shading by shrubs, further reduce the

742 competitive abilities of the graminoids. In contrast to the latter example, extremely low spring

743 snow accumulation is projected to occur over much of the Northern Hemisphere, with $>80 \%$ of

744 years below the baseline minimum in some areas by 2080-2099 (Diffenbaugh \& Field, 2013).

745 The resulting decreases in melt water in spring, coupled with increased evapotranspiration and

746 decreased summer rainfall in some regions, will increase summer drought severity. 
As we have demonstrated in this section, understanding the interactions between climate

748 and biotic processes is essential for predicting how ecosystems will respond to climatic warming

749 (Blois et al., 2013). Moving forward, integrating the responses of organisms across entire

750 ecosystems, while taking into account linkages between winter and summer responses to climate

751 change, and differing capacity to evolve, is a daunting task. This task will be facilitated by $a$

752 priori identification of the key vulnerabilities to winter climate change, a process which is

753 described in the following section.

754

755

VI. Predicting vulnerability to winter climate change

756

It is clear that winter is an important driver of biological processes and organismal

757 fitness, and that winter climate change has the potential to significantly impact individuals,

758 populations, community interactions and ecosystem processes. However, if a goal of global

759 change research is to offer predictive power to facilitate risk assessments and management

760 decisions, then it is necessary to identify which species and processes will be vulnerable to

761 changing winters.

762 Williams et al. (2008) proposed an integrative framework to identify and prioritise

763 species that are vulnerable to climate change, where vulnerability was defined as susceptibility of

764 a system to change - in most of our cases, the primary 'system' we consider is an individual or

765 population. The authors distinguished between factors determining exposure to a change in

766 climate, and those determining sensitivity to those changes. In their framework, exposure was

767 determined by the degree of regional climate change, filtered through microclimatic buffering

768 due to habitat choice. For example, if temperatures are rising, a species that does not have the

769 capacity to change microhabitat choice or alter thermoregulatory behaviour will be exposed to an

770 increase in temperature, whereas a species that can buffer these regional changes will not 
771 (Kearney, Shine \& Porter, 2009). In the context of winter, the three primary drivers of changing

772 snow cover, thermal variability, and shifts in mean temperature interact with overwintering

773 biology to modify the stresses that will be experienced: thus we must understand the causal

774 relationships between the drivers that determine exposure to winter climate change. Figure 3 can

775 be used as a framework for determining exposure to stress resulting from winter climate change,

776 although such predictions are still dependent on predicting changes in the drivers from climate

777 data and models - a major challenge given the discrepancy between the size of organisms and

778 the scale at which climate data are collected (Potter, Woods \& Pincebourde, 2013), and the lack

779 of information about the timeframes over which selection will modify winter phenology and

780 physiology.

781 Assuming that we can accurately assess an organism's exposure to climate change, the

782 next step is to determine whether it will be sensitive (i.e. experience negative impacts). Williams

783 et al. (2008) suggest that sensitivity is governed by intrinsic ecological, physiological or genetic

784 traits of the focal species that determine levels of resilience (the ability of a species to survive

785 and recover from a negative impact) and adaptive capacity (the capacity for plastic or

786 evolutionary changes to reduce negative impacts). Related to the capacity for adaptation, we

787 note that estimates of the strength of selection encountered by organisms in winter environments

788 are an essential component of a predictive framework, but to date few studies have measured

789 such selection gradients (Boratynski et al. (2010) provide one example of this). In using Figure 3

790 as a framework, it is possible not only to identify the potential exposure to stress resulting from

791 changes in the drivers, but because it makes clear (some of) the causal links between the drivers

792 and organismal fitness, it allows the identification of end traits - and the design of simple

793 experiments - that facilitate an assessment of the susceptibility of organisms to changes in those 
794 drivers. For example, there are clear links between overwintering temperature and energy

795 consumption for many overwintering ectotherms. It is thus possible to design a simple

796 experiment (e.g. keep overwintering stages of several species at several temperatures; Williams

797 et al., 2012a) to compare susceptibility of energy use to changes in temperature. Similarly,

798 experimental designs are now well established for determining impacts of repeated stress

799 exposure (Marshall \& Sinclair, 2012a), addressing the impacts of shifting variability or snow

800 cover - although the results of such experiments are not necessarily easy to interpret. For

801 example, repeated freezing in overwintering caterpillars saves energy (Marshall \& Sinclair,

802 2012b) but has other sub-lethal impacts (Marshall \& Sinclair, 2011). Thus, a reductionist

803 approach can be used to identify or rule out susceptibility to certain drivers of climate change

804 relatively rapidly, but more complex experiments are necessary to understand interactions among 805 drivers.

806 More generally, it is possible to identify some of the general traits that render individuals

807 or populations of a species vulnerable (or resilient) to winter climate change (Table 1). As with

808 all sensitivity to climate change, species that have high rates of reproduction and short lifecycles,

809 large range sizes (but not large spatial scales of operation), and high dispersal will be less

810 vulnerable to change (Williams et al., 2008). However, the links in Figure 3 allow the

811 identification of winter-specific traits that lead to vulnerability; some of these are outlined in

812 Table 1, and are grouped according to energy balance (e.g. thermoregulatory strategy,

813 metabolism), phenology (e.g. chilling requirements, overwintering stage), cold injury (e.g. cold

814 tolerance, response to repeated stress), water balance and predation (e.g. trophic position,

815 predatory avoidance strategies). 
816 Despite extensive evidence from individual cases for the importance of trophic dynamics

817 in determining overwinter responses, they remain difficult to predict. Community-level

818 experiments are inherently complex and limited in spatial and temporal scope, while the use of

819 population-based data to construct dynamic models of communities is typically inadequate for

820 predicting responses to novel combinations of drivers, even in the growing season (Abrams,

821 2001). This complexity is intensified when the relative performances of organisms both over

822 summer and winter must be taken into account, but we propose that the species-based $a$ priori

823 approach, based on the drivers and vulnerabilities identified in Table 1 and Figure 3 can be used

824 to identify key impacts of winter. If combined with an understanding of the community

825 interactions in a system, it is possible to at least identify potential responses to winter climate

826 change at the community level.

827

828 VII. A call to further integrate winter into climate change research

829 Winter imposes a severe selective pressure that determines fitness, drives many

830 ecological processes, and shapes the evolution of organisms. The pressing need to understand

831 the mechanisms underlying biological responses to climate change, coupled with the rapid

832 changes in winter conditions, together provide a strong imperative to unravel the complexities of

833 responses to winter at the individual, community, and ecosystem scales, and to determine general

834 patterns describing vulnerability to negative impacts. To integrate this information we must

835 combine theoretical and empirical approaches and synthesise across taxa, levels of organisation,

836 and climate drivers.

837 For theorists, the challenge lies in incorporating winter into models that tend to have

838 forms and parameters associated with growth and assimilation, rather than dormancy and

839 consumption (although there is scope for the latter in Dynamic Energy Budget models; Sousa et 
840 al., 2010). Mechanistic models of winter biology exist for some species, and the form of some of 841 these models may be incorporated into existing frameworks, and potentially expanded to include 842 additional aspects of winter climate change. For example, Régnière and Bentz (2007) have 843 provided a robust model of the dynamic shifts in cold tolerance of overwintering mountain pine 844 beetles, although this model does not incorporate any sub-lethal impacts of cold exposure. 845 Because it is likely that the existing relationships between climate variables will be disrupted 846 (Jackson et al., 2009; see also Figure 2), functional or phylogenetic approaches may be powerful 847 alternatives to existing niche models (Buckley \& Kingsolver, 2012) by using existing studies to 848 infer potential impacts of combinations of winter drivers that may be novel for a given species or 849 population. However, data regarding the effects of winter conditions on fitness is sparse and 850 diffuse, and not necessarily in a model-ready format. Trait databases such as iPlant (Goff et al., 851 2011) may provide a source of such information, but theorists and empiricists will need to work 852 together to identify the key traits that will inform vulnerability to winter climate change, using 853 approaches similar to those outlined in Figure 3 and Table 1.

854 To inform this theoretical effort, empiricists need to collect more data on the performance 855 and, ultimately, fitness consequences of projected changes in winter climate drivers. Such an 856 understanding requires integration across levels of organisation and from regional to single857 organism scales; this entails a shift in focus to populations rather than species, metres rather than 858 miles, and minutes rather than months. A lofty goal for mechanistic studies of overwintering 859 biology is the development of general principles that describe how organisms respond to winter, 860 and the ability to predict - a priori - which species will be most vulnerable to winter climate 861 change. To accomplish this we must extend more laboratory studies into the field, which will 862 require methodological limitations and biases to be overcome. For example, methods for 
863 simulating winter climate change in the field, such as snow fences, snow removal, heated soil 864 cables and overhead heaters, are often plagued by artifacts or scaling limitations (Shen \& Harte, 865 2000). Similarly, there is a need to expand the geographic and taxonomic focus of winter 866 biology. There has been a disproportionate focus on relatively cold environments with long 867 winters (such as the high arctic) relative to temperate systems (Kreyling, 2010), and there have 868 also been asymmetries in research between the northern and southern hemispheres, which may 869 also bias our understanding of the key aspects of winter (Chown et al., 2004). Throughout this 870 review, it is apparent that the bulk of the literature on some broadly-applicable topics is 871 constrained to certain systems; for example, many studies of winter climate change at the 872 community and population levels have been conducted on arctic mammals, but few on temperate 873 insects, whereas a disproportionate amount of research has been conducted on the physiological 874 responses to freezing of temperate insects and crop plants. Finally, there is a need for substantial 875 effort documenting fall and winter events complementing the successful and ongoing 876 documentation of changes in spring phenology and growing season biology. We particularly 877 encourage a concerted effort to expand existing, well-characterised, systems into the winter to 878 develop a more holistic view of how organisms, communities, and ecosystems will respond to 879 climate change.

881 VIII. Conclusions

882 (1) Overwintering biology is a key component of the biology of organisms that live in 883 temperate, polar and alpine habitats, and has driven the evolution of extreme phenotypes such as dormancy and migration. 
885

886

887

888

889

890

891

892

893

894

895

896

897

898

899

900

901

902

903

904

905

906

907

(2) The main abiotic drivers of biological responses to winter are the mean and variability of air temperatures and the extent and timing of snow cover. All of these are being affected by climate change in a regionally-specific manner.

(3) Understanding the links between abiotic change and organismal performance is important for determining organismal vulnerability to climate change. This will require a mechanistic and integrative approach.

(4) Responses to winter conditions are not isolated from growing season responses to climate. Therefore it is important to investigate the impacts of winter on performance, fitness and biotic interactions in the context of growing season biology. We suggest that an opportunity exists to extend existing long-term studies of growing season biology to incorporate the effects of winter.

(5) At the population and community levels, inter- and intra-specific interactions strongly influence responses to winter climate change. Impacts on individual species will propagate through ecosystems, and the role of winter in modifying these interactions must be considered when predicting the ecological impacts of climate change.

\section{Acknowledgements}

Thanks to Dan Hahn, Jessica Hellmann, Jack Millar, Katie Marshall, Mhairi McFarlane and two anonymous referees for constructive criticism of earlier drafts of the ms, to Mary Power for helpful discussions, and to Ken Miller, Heath MacMillan and Hiroko Udaka for assistance with the figures.

\section{References}


908 AARS, J. \& IMS, R. A. (2002). Intrinsic and climatic determinants of population demography: The 909 winter dynamics of tundra voles. Ecology 83, 3449-3456.

910 ABRAMS, P. A. (2001). Describing and quantifying interspecific interactions: a commentary on 911 recent approaches. Oikos 94, 209-218.

912 ACIA. (2005). Arctic Climate Impact Assessment. Cambridge University Press, Cambridge. 913 Addington, R. N. \& SeAstedt, T. R. (1999). Activity of soil microarthropods beneath snowpack in alpine tundra and subalpine forest. Pedobiologia 43, 47-53.

Alerstam, T., Hedenstrom, A. \& Akesson, S. (2003). Long-distance migration: evolution and determinants. Oikos 103, 247-260.

AmASINO, R. (2004). Vernalization, competence, and the epigenetic memory of Winter. Plant Cell 16, 2553-2559.

919 Angilletta, M. J. (2009). Thermal Adaptation. Oxford University Press, New York.

920 Augspurger, C. K. (2009). Spring 2007 warmth and frost: phenology, damage and refoliation in 921 a temperate deciduous forest. Functional Ecology 23, 1031-1039.

922 Augspurger, C. K. (2013). Reconstructing patterns of temperature, phenology, and frost 923 damage over 124 years: Spring damage risk is increasing. Ecology 94, 41-50.

924

925

926

927 AwMACK, C. S. \& LEATHER, S. R. (2002). Host plant quality and fecundity in herbivorous 928 insects. Annual Review of Entomology 47, 817-844.

929 930

Aukema, B. H., Carroll, A. L., Zheng, Y., Zhu, J., Raffa, K. F., Moore, R. D., Stahl, K. \& TAYLOR, S. W. (2008). Movement of outbreak populations of mountain pine beetle: influences of spatiotemporal patterns and climate. Ecography 31, 348-358. 
931 Battisti, A., Stastny, M., Netherer, S., Robinet, C., Schopf, A., Roques, A. \& Larsson, S. 932 (2005). Expansion of geographic range in the pine processionary moth caused by 933 increased winter temperatures. Ecological Applications 15, 2084-2096.

934 Ben-Hamo, M., Munoz-Garcia, A., Williams, J. B., Korine, C. \& Pinshow, B. (2013). 935 Waking to drink: rates of evaporative water loss determine arousal frequency in hibernating bats. Journal of Experimental Biology 216, 573-577.

Berger, S., Sohlke, G., Walther, G. R. \& Pott, R. (2007). Bioclimatic limits and range shifts of cold-hardy evergreen broad-leaved species at their northern distributional limit in Europe. Phytocoenologia 37, 523-539.

Blois, J. L., Zarnetske, P. L., FitzPatrick, M. C. \& Finnegan, S. (2013). Climate Change and the Past, Present, and Future of Biotic Interactions. Science 341, 499-504.

Boggs, C. L. \& FreEman, K. D. (2005). Larval food limitation in butterflies: effects on adult resource allocation and fitness. Oecologia 144, 353-361.

944 BogGs, C. L. \& InOUYE, D. W. (2012). A single climate driver has direct and indirect effects on insect population dynamics. Ecology Letters 15, 502-508.

946 Bokhorst, S., Bjerke, J. W., Street, L. E., Callaghan, T. V. \& PhoeniX, G. K. (2011). Impacts of multiple extreme winter warming events on sub-Arctic heathland: phenology,

Bokhorst, S., Phoenix, G. K., Bjerke, J. W., Callaghan, T. V., Huyer-Brugman, F. \& BERG, M. P. (2012a). Extreme winter warming events more negatively impact small rather than large soil fauna: shift in community composition explained by traits not taxa. Global Change Biology 18, 1152-1162. 
o

W

$\mathrm{t}$

949 Bokhorst, S., Phoenix, G. K., Bjerke, J. W., Callaghan, T. V., Huyer-Brugman, F. \& 950 BERG, M. P. (2012a). Extreme winter warming events more negatively impact small 951 rather than large soil fauna: shift in community composition explained by traits not taxa. 952 Global Change Biology 18, 1152-1162.

$\mathrm{n}$

d 
953 Bokhorst, S., Tommervik, H., Callaghan, T. V., Phoenix, G. K. \& BJerke, J. W. (2012b). 954 955 956 Vegetation recovery following extreme winter warming events in the sub-Arctic estimated using NDVI from remote sensing and handheld passive proximal sensors. Environmental and Experimental Botany 81, 18-25.

957 Bonan, G. B. (2003). Ecological Climatology. Cambridge University Press, Cambridge. 958 Boratynski, Z., Koskela, E., Mappes, T. \& OKSAnen, T. A. (2010). Sex-specific selection on 959 energy metabolism - selection coefficients for winter survival. Journal of Evolutionary Biology 23, 1969-1978.

Both, C., van Asch, M., BiJlsma, R. G., van Den Burg, A. B. \& Visser, M. E. (2009). Climate change and unequal phenological changes across four trophic levels: constraints or adaptations? Journal of Animal Ecology 78, 73-83.

964 Bradshaw, W. E. \& Holzapfel, C. M. (2001). Genetic shift in photoperiodic response 965 correlated with global warming. Proceedings of the National Academy of Sciences of the

971 Brown, P. J. \& DeGaetano, A. T. (2011). A paradox of cooling winter soil surface 972 temperatures in a warming northeastern United States. Agricultural and Forest 973 Meteorology 151, 947-956. 
974 Buckley, L. B. \& Kingsolver, J. G. (2012). Functional and Phylogenetic Approaches to

975 Forecasting Species' Responses to Climate Change. Annual Review of Ecology,

$976 \quad$ Evolution, and Systematics 43, 205-226.

977 Bykova, O. \& SAGE, R. F. (2012). Winter cold tolerance and the geographic range separation of

978 Bromus tectorum and Bromus rubens, two severe invasive species in North America.

979 Global Change Biology 2012, 3654-3663.

980 Callaghan, T. V., Buorn, L. O., Chernov, Y., Chapin, T., Christensen, T. R., Huntley, B.,

981 Ims, R. A., Johansson, M., Jolly, D., Jonasson, S., Matveyeva, N., Panikov, N.,

982 Oechel, W., Shaver, G. \& HentTOnEN, H. (2004). Effects on the structure of arctic

983 ecosystems in the short- and long-term perspectives. $A M B I O \mathbf{3 3}, 436-447$.

984 CAPRiO, J. M., QuAmme, H. A. \& ReDmond, K. T. (2009). A statistical procedure to determine

985 recent climate change of extreme daily meteorological data as applied at two locations in

$986 \quad$ Northwestern North America. Climatic Change 92, 65-81.

987 Chen, I. C., Hill, J. K., Ohlemuller, R., Roy, D. B. \& ThOmas, C. D. (2011a). Rapid Range

988 Shifts of Species Associated with High Levels of Climate Warming. Science 333, 1024-

$989 \quad 1026$.

990 Chen, I. C., Hill, J. K., Shiu, H. J., Holloway, J. D., Benedick, S., Chey, V. K., Barlow, H.

991 S. \& ThOMAS, C. D. (2011b). Asymmetric boundary shifts of tropical montane

992 Lepidoptera over four decades of climate warming. Global Ecology and Biogeography

$993 \quad 20,34-45$.

994 Chown, S. L., Sinclair, B. J., LeinaAs, H. P. \& Gaston, K. J. (2004). Hemispheric

995 asymmetries in biodiversity - A serious matter for ecology. PLoS Biology 2, e406. 
996 Chown, S. L., Slabber, S., McGeoch, M. A., Janion, C. \& LeinaAs, H. P. (2007). Phenotypic 997 plasticity mediates climate change responses among invasive and indigenous arthropods. $998 \quad$ Proceedings of the Royal Society B 274, 2531-2537.

999 CoOK, B. I., Wolkovich, E. M. \& Parmesan, C. (2012). Divergent responses to spring and 1000 winter warming drive community level flowering trends. Proceedings of the National 1001 Academy of Sciences of the United States of America 109, 9000-9005.

1002 Coulson, S. J., LeinaAs, H. P., IMS, R. A. \& SøviK, G. (2000). Experimental manipulation of 1003 the winter surface ice layer: the effects on a High Arctic soil microarthropod community. 1004 Ecography 23, 299-306.

1005 CROZIER, L. (2004). Warmer winters drive butterfly range expansion by increasing survivorship. 1006 Ecology 85, 231-241.

1007 Daly, C., Widrlechner, M. P., Halbleib, M. D., Smith, J. I. \& Gibson, W. P. (2012). 1008 Development of a New USDA Plant Hardiness Zone Map for the United States. Journal 1009 of Applied Meteorology and Climatology 51, 242-264.

1010 1011

1012

1013

DeERE, J. A. \& ChOwn, S. L. (2006). Testing the beneficial acclimation hypothesis and its 1014 alternatives for locomotor performance. American Naturalist 168, 630-644.

1015 Deser, C., Tomas, R., Alexander, M. \& Lawrence, D. (2010). The Seasonal Atmospheric 1016 Response to Projected Arctic Sea Ice Loss in the Late Twenty-First Century. Journal of 1017 Climate 23, 333-351. 
1018 Diamond, S. E., Frame, A. M., Martin, R. A. \& Buckley, L. B. (2011). Species' traits predict 1019 phenological responses to climate change in butterflies. Ecology Letters 92, 1005-1012. 1020 Diffenbaugh, N. S. \& FIELD, C. B. (2013). Changes in Ecologically Critical Terrestrial Climate $1021 \quad$ Conditions. Science 341, 486-492.

1022 Dionne, J., Castonguay, Y., NAdeau, P. \& Desjardins, Y. (2001). Freezing tolerance and 1023 carbohydrate changes during cold acclimation of green-type annual bluegrass (Poa annua 1024 L.) ecotypes. Crop Science 41, 443-451.

1025 Durán, J., Rodríguez, A., Morse, J. L. \& Groffman, P. M. (2013). Winter climate change 1026 effects on soil C and N cycles in urban grasslands. Global Change Biology 19, 28262837.

1028 Easterling, D. R., Meehl, G. A., Parmesan, C., Changnon, S. A., Karl, T. R. \& Mearns, L. 1029 O. (2000). Climate extremes: Observations, modeling, and impacts. Science 289, 20682074.

1031 ENSMinger, I., Busch, F. \& HÜNER, N. P. A. (2006). Photostasis and cold acclimation: sensing 1032 low temperature through photosynthesis. Physiologia Plantarum 126, 28-44.

1033 Estes, J. A., Terborgh, J., Brashares, J. S., Power, M. E., Berger, J., Bond, W. J., 1034 Carpenter, S. R., Essington, T. E., Holt, R. D., Jackson, J. B. C., Marquis, R. J., 1035 Oksanen, L., Oksanen, T., Paine, R. T., Pikitch, E. K., Ripple, W. J., SAndin, S. A., 1036 Scheffer, M., Schoener, T. W., Shurin, J. B., Sinclair, A. R. E., Soule, M. E., 1037 Virtanen, R. \& Wardle, D. A. (2011). Trophic Downgrading of Planet Earth. Science $1038 \quad 333,301-306$. 
1039 FEDER, J. L., Hunt, T. A. \& Bush, G. L. (1993). The effects of climate, host-plant phenology and 1040 host fidelity on the genetics of apple and hawthorn infesting races of Rhagoletis pomonella. Entomologia Experimentalis Et Applicata 69, 117-135.

Foden, W. B., Butchart, S. H. M., Stuart, S. N., Vie, J. C., Akcakaya, H. R., Angulo, A., DeVantier, L. M., Gutsche, A., Turak, E., Cao, L., Donner, S. D., Katariya, V., Bernard, R., Holland, R. A., Hughes, A. F., O'Hanlon, S. E., Garnett, S. T., 1045 1046 1047 1048 1049 1050 SeKercioglu, C. H. \& MACE, G. M. (2013). Identifying the World's Most Climate Change Vulnerable Species: A Systematic Trait-Based Assessment of all Birds, Amphibians and Corals. Plos One 8, 13.

ForRest, J. R. K. \& THOMSON, J. D. (2011). An examination of synchrony between insect emergence and flowering in Rocky Mountain meadows. Ecological Monographs 81, 469491.

1051 Fox, L. R., Ribeiro, S. P., Brown, V. K., Masters, G. J. \& Clarke, I. P. (1999). Direct and 1052 indirect effects of climate change on St John's wort, Hypericum perforatum L.

1054 FRIDLEY, J. D. (2012). Extended leaf phenology and the autumn niche in deciduous forest 1055 invasions. Nature 485, 359-362.

1056 FULLER, T. K. (1991). Effect of snow depth on wolf activity and prey selection in north-central 1057 Minnesota. Canadian Journal of Zoology 69, 283-287.

1058 Gaines, S. D. \& Denny, M. W. (1993). The Largest, Smallest, Highest, Lowest, Longest, and 1059 Shortest: Extremes in Ecology. Ecology 74, 1677-1692.

1060 Gentle, L. K. \& Gosler, A. G. (2001). Fat reserves and perceived predation risk in the great tit, 1061 Parus major. Proceedings of the Royal Society of London B 268, 487-491. 
1062 Gilg, O., Kovacs, K. M., Aars, J., Fort, J., Gauthier, G., Gremillet, D., IMs, R. A.,

1063

1064

1065

1066

1067

1068

1069

1070

1071

1072

1073

1074

1075

1076

1077

1078

1079

1080

1081

1082

1083

1084
Meltofte, H., Moreau, J., Post, E., Schmidt, N. M., Yannic, G. \& Bollache, L.

(2012). Climate change and the ecology and evolution of Arctic vertebrates. Annals of the New York Academy of Sciences 1249, 166-190.

Gilg, O., SitTLER, B. \& HANSKI, I. (2009). Climate change and cyclic predator-prey population dynamics in the high Arctic. Global Change Biology 15, 2634-2652.

Goff, S. A., Vaughn, M., McKay, S., Lyons, E., Stapleton, A. E., Gessler, D., Matasci, N., Wang, L., Hanlon, M., Lenards, A., Muir, A., Merchant, N., Lowry, S., Mock, S., Helmke, M., Kubach, A., NARro, M., Hopkins, N., Micklos, D., Hilgert, U., Gonzales, M., Jordan, C., Skidmore, E., Dooley, R., CaZes, J., McLay, R., Lu, Z., Pasternak, S., Koesterke, L., Piel, W. H., Grene, R., Noutsos, C., Gendler, K., Feng, X., Tang, C., Lent, M., Kim, S.-J., Kvilekval, K., Manjunath, B. S., Tannen, V., Stamatakis, A., Sanderson, M., Welch, S. M., Cranston, K., Soltis, P., Soltis, D., O'Meara, B., Ane, C., Brutnell, T., Kleibenstein, D. J., White, J. W., LeebensMack, J., Donoghue, M. J., Spalding, E. P., Vision, T. J., Myers, C. R., Lowenthal, D., Enquist, B. J., Boyle, B., Akoglu, A., Andrews, G., Ram, S., Ware, D., Stein, L. \& Stanzione, D. (2011). The iPlant Collaborative: Cyberinfrastructure for Plant Biology. Frontiers in Plant Science 2.

GotThard, K., Nylin, S. \& WikLund, C. (1999). Seasonal plasticity in two satyrine butterflies: state-dependent decision making in relation to daylength. Oikos $\mathbf{8 4}, 453-462$.

GotThard, K., Nylin, S. \& WikLund, C. (2000). Individual state controls temperature dependence in a butterfly (Lasiommata maera). Proceedings of the Royal Society of London B 267, 589-593. 
1085 Groffman, P. M., Driscoll, C. T., FAhey, T. J., Hardy, J. P., Fitzhugh, R. D. \& Tierney, G. 1086 L. (2001). Colder soils in a warmer world: A snow manipulation study in a northern hardwood forest ecosystem. Biogeochemistry 56, 135-150.

Gu, L., Hanson, P. J., Mac Post, W., Kaiser, D. P., Yang, B., Nemani, R., Pallardy, S. G. \& MEYERS, T. (2008). The 2007 eastern US spring freezes: Increased cold damage in a warming world? Bioscience 58, 253-262.

Guerra, P. A. \& REPPERT, S. M. (2013). Coldness triggers northward flight in remigrant 1092 monarch butterflies. Current Biology 23, 419-423.

Guillemain, M., Elmberg, J., Arzel, C., Johnson, A. R. \& Simon, G. (2008). The incomecapital breeding dichotomy revisited: late winter body condition is related to breeding success in an income breeder. Ibis 150, 172-176.

Hahn, D. A. \& Denlinger, D. L. (2011). Energetics of Insect Diapause. Annual Review of Entomology 56, 103-121.

Hansen, B. B., Aanes, R., Herfindal, I., Kohler, J. \& Saether, B. E. (2011). Climate, icing, and wild arctic reindeer: past relationships and future prospects. Ecology 92, 1917-1923.

1100 Henry, H. A. L. (2008). Climate change and soil freezing dynamics: historical trends and 1101 projected changes. Climatic Change 87, 421-434.

1102 Hill, J. K., Griffiths, H. M. \& Thomas, C. D. (2011). Climate Change and Evolutionary 1103 Adaptations at Species' Range Margins. Annual Review of Entomology 56, 143-159. 1104 Hill, J. K., Thomas, C. D., Fox, R., Telfer, M. G., Willis, S. G., Asher, J. \& Huntley, B. 1105 (2002). Responses of butterflies to twentieth century climate warming: implications for 1106 future ranges. Proceedings of the Royal Society of London B 269, 2163-2171. 
1107 Hodges, K. E., BoOnStRA, R. \& KREBS, C. J. (2006). Overwinter mass loss of snowshoe hares in 1108 the Yukon: starvation, stress, adaptation or artefact? Journal of Animal Ecology 75, 1-13.

1109 Høye, T. T., Post, E., Meltofte, H., Schmidt, N. M. \& Forchhammer, M. C. (2007). Rapid 1110 advancement of spring in the High Arctic. Current Biology 17, R449-R451.

1111 Høye, T. T., Post, E., Schmidt, N. M., Trøjelsgand, K. \& Forchhammer, M. C. (2013). 1112 Shorter flowering seasons and declining abundance of flower visitors in a warmer Arctic. $1113 \quad$ Nature Clim. Change 3, 759-763.

1114 Hufkens, K., Friedl, M. A., Keenan, T. F., Sonnentag, O., Bailey, A., O'Keefe, J. \& 1115 RICHARDSON, A. D. (2012). Ecological impacts of a widespread frost event following 1116 early spring leaf-out. Global Change Biology 18, 2365-2377.

1117 Humphries, M. M., Thomas, D. W. \& SpeAKMAn, J. R. (2002). Climate-mediated energetic 1118 constraints on the distribution of hibernating mammals. Nature 418, 313-316.

1119 INOUYE, D. W. (2008). Effects of climate change on phenology, frost damage, and floral 1120 abundance of montane wildflowers. Ecology 89, 353-362.

Inouye, D. W., BARr, B., Armitage, K. B. \& InOuYe, B. D. (2000). Climate change is affecting 1122

1123 1124 1125 altitudinal migrants and hibernating species. Proceedings of the National Academy of Sciences of the United States of America 97, 1630-1633.

IPCC. (2007). Climate Change 2007: Synthesis report. Intergovernmental Panel on Climate Change, Geneva.

1126 IRWIN, J. T. \& LEE, R. E. (2003). Cold winter microenvironments conserve energy and improve 1127 overwintering survival and potential fecundity of the goldenrod gall fly, Eurosta 1128 solidaginis. Oikos 100, 71-78. 
1129 Jackson, S. T., Betancourt, J. L., BoOth, R. K. \& GRAY, S. T. (2009). Ecology and the ratchet 1130 of events: Climate variability, niche dimensions, and species distributions. Proceedings 1131 of the National Academy of Sciences of the United States of America 106, 19685-19692.

1132 JeOng, S. J., Ho, C. H., Gim, H. J. \& Brown, M. E. (2011). Phenology shifts at start vs. end of 1133 growing season in temperate vegetation over the Northern Hemisphere for the period 1134 1982-2008. Global Change Biology 17, 2385-2399.

1135 Jepsen, J. U., Kapari, L., Hagen, S. B., Schott, T., Vindstad, O. P. L., Nilssen, A. C. \& Ims, 1136 R. A. (2011). Rapid northwards expansion of a forest insect pest attributed to spring 1137 phenology matching with sub-Arctic birch. Global Change Biology 17, 2071-2083.

1138 Jiguet, F., Gadot, A. S., Julliard, R., Newson, S. E. \& Couvet, D. (2007). Climate envelope, 1139 life history traits and the resilience of birds facing global change. Global Change Biology $1140 \quad \mathbf{1 3}, 1672-1684$.

1141 Joshi, A., Olson, D. L. \& CAREY, D. R. (2009). Overwintering Survival of Aphthona Beetles 1142 (Coleoptera: Chrysomelidae): A Biological Control Agent of Leafy Spurge Released in 1143 North Dakota. Environmental Entomology 38, 1539-1545.

1144 KANDA, L. L. (2005). Winter energetics of Virginia opossums Didelphis virginiana and 1145 implications for the species' northern distributional limit. Ecography 28, 731-744. 1146 Karl, I., Stoks, R., Bauerfeind, S. S., Dierks, A., Franke, K. \& Fischer, K. (2013). No 1147 Trade-Off between Growth Rate and Temperature Stress Resistance in Four Insect $1148 \quad$ Species. PLoS ONE 8, e62434.

1149 Kausrud, K. L., Mysterud, A., Steen, H., Vik, J. O., Ostbye, E., Cazelles, B., Framstad, 1150 E., Eikeset, A. M., Mysterud, I., Solhoy, T. \& Stenseth, N. C. (2008). Linking $1151 \quad$ climate change to lemming cycles. Nature 456, 93-U3. 
1152 KeARney, M., Shine, R. \& PORTER, W. P. (2009). The potential for behavioral thermoregulation

1153

1154

1155

1156

1157

1158

1159

1160

1161

1162

1163

1164

1165

1166

1167

1168

1169

1170

1171

1172

1173

1174 to buffer "cold-blooded" animals against climate warming. Proceedings of the National Academy of Sciences of the United States of America 106, 3835-3840.

Klok, C. J., Chown, S. L. \& Gaston, K. J. (2003). The geographical range structure of the Holly Leaf-miner. III. Cold hardiness physiology. Functional Ecology 17, 858-868.

KORSLUND, L. \& STEEN, H. (2006). Small rodent winter survival: snow conditions limit access to food resources. Journal of Animal Ecology 75, 156-166.

KREYLING, J. (2010). Winter climate change: a critical factor for temperate vegetation performance. Ecology 91, 1939-1948.

Kreyling, J. \& Henry, H. A. L. (2011). Vanishing winters in Germany: soil frost dynamics and snow cover trends, and ecological implications. Climate Research 46, 269-276.

Kreyling, J., Jentsch, A. \& Beierkuhnlein, C. (2011). Stochastic trajectories of succession initiated by extreme climatic events. Ecology Letters 14, 758-764.

KunKel, K. E., EAsterling, D. R., HubBARD, K. \& REDMOND, K. (2004). Temporal variations in frost-free season in the United States: 1895-2000. Geophysical Research Letters 31, L03201.

Kurian, L. M., Lautz, L. K. \& Mitchell, M. J. (2013). Winter Hydrology and NO3Concentrations in a Forested Watershed: A Detailed Field Study in the Adirondack Mountains of New York. Journal of the American Water Resources Association 49, 264283.

Kurz, W. A., Dymond, C. C., Stinson, G., Rampley, G. J., Neilson, E. T., Carroll, A. L., EBATA, T. \& SAFRANYIK, L. (2008). Mountain pine beetle and forest carbon feedback to climate change. Nature 452, 987-990. 
1175 Lane, J. E., Kruuk, L. E., Charmantier, A., Murie, J. O. \& Dobson, F. S. (2012). Delayed 1176 phenology and reduced fitness associated with climate change in a wild hibernator. Nature 489, 554-7.

LeAther, S. R., WAlters, K. F. A. \& BALE, J. S. (1993). The Ecology of Insect Overwintering. Cambridge University Press, Cambridge.

LIU, X. D., YIN, Z. Y., SHAO, X. M. \& QIN, N. S. (2006). Temporal trends and variability of daily maximum and minimum, extreme temperature events, and growing season length over the eastern and central Tibetan Plateau during 1961-2003. Journal of Geophysical Research-Atmospheres 111, D19109

LOWE. (2005). IPCC DDC AR4 UKMO-HadCM3 SRESA2 run1. CERA-DB "UKMO_HadCM3_SRESA2_1"..

Luedeling, E., Girvetz, E. H., Semenov, M. A. \& Brown, P. H. (2011). Climate Change Affects Winter Chill for Temperate Fruit and Nut Trees. PLoS One 6, e20155.

Margesin, R., Neuner, G. \& Storey, K. B. (2007). Cold-loving microbes, plants, and animalsfundamental and applied aspects. Naturwissenschaften 94, 77-99.

1190 Marshall, K. E. \& SinClaIR, B. J. (2010). Repeated stress exposure results in a survival1191 reproduction trade-off in Drosophila melanogaster. Proceedings of the Royal Society B 277, 963-969.

1193 Marshall, K. E. \& SinclaiR, B. J. (2011). The sub-lethal effects of repeated freezing in the $1194 \quad$ woolly bear caterpillar Pyrrharctia isabella. Journal of Experimental Biology 214, 120511951212.

1196 MARShall, K. E. \& Sinclair, B. J. (2012a). The impacts of repeated cold exposure on insects. 1197 Journal of Experimental Biology 215, 1607-1613. 
1198 MARShall, K. E. \& SinClaiR, B. J. (2012b). Threshold temperatures mediate the impact of 1199 reduced snow cover on overwintering freeze-tolerant caterpillars. Naturwissenschaften $1200 \quad 99,33-41$.

1201 Martin, T. \& MARON, J. (2012). Climate impacts on bird and plant communities from altered 1202 animal-plant interactions. Nature Climate Change 2, 195-200.

1203 MATZNER, E. \& BORKEN, W. (2008). Do freeze-thaw events enhance C and N losses from soils 1204 of different ecosystems? A review. European Journal of Soil Science 59, 274-284.

1205 MAYR, S., Gruber, A. \& BAUER, H. (2003). Repeated freeze-thaw cycles induce embolism in 1206 drought stressed conifers (Norway spruce, stone pine). Planta 217, 436-441.

1207 Muir, T. J., Dishong, B. D., LeE, R. E. \& Costanzo, J. P. (2013). Energy use and management 1208 of energy reserves in hatchling turtles (Chrysemys picta) exposed to variable winter 1209 conditions. Journal of Thermal Biology 38, 324-330.

1210 Neuvonen, S., Niemelä, P. \& Virtanen, T. (1999). Climatic Change and insect outbreaks in 1211 1212

Olofsson, J., Oksanen, L., Callaghan, T., Hulme, P. E., Oksanen, T. \& Suominen, O. 1213 (2009). Herbivores inhibit climate-driven shrub expansion on the tundra. Global Change $1214 \quad$ Biology 15, 2681-2693.

1215 Ozgul, A., Childs, D. Z., Oli, M. K., Armitage, K. B., Blumstein, D. T., Olson, L. E., 1216 Tuljapurkar, S. \& COUlson, T. (2010). Coupled dynamics of body mass and 1217 population growth in response to environmental change. Nature 466, 482-U5.

1218 OzTAS, T. \& FAYETORBAy,F. (2003). Effect of freezing and thawing processes on soil aggregate $1219 \quad$ stability. Catena 52, 1-8. 
1220

1221

1222

1223

1224

1225

1226

1227

1228

1229

1230

1231

1232

1233

1234

1235

1236

1237

1238

1239

1240

1241

Parmesan, C., Ryrholm, N., Stefanescu, C., Hill, J. K., Thomas, C. D., Descimon, H., Huntley, B., Kaila, L., Kullberg, J., Tammaru, T., Tennent, W. J., Thomas, J. A. \& WARREN, M. (1999). Poleward shifts in geographical ranges of butterfly species associated with regional warming. Nature 399, 579-583.

Pauli, J. N., Zuckerberg, B., Whiteman, J. P. \& Porter, W. (2013). The subnivium: a deteriorating seasonal refugium. Frontiers in Ecology and the Environment 11, 260-267.

Pelini, S. L., Dzurisin, J. D. K., Prior, K. M., Williams, C. M., Marsico, T. D., Sinclair, B. J. \& HellmanN, J. J. (2009). Translocation experiments with butterflies reveal limits to enhancement of poleward populations under climate change. Proceedings of the National Academy of Sciences of the United States of America 106, 11160-11165.

Persson, I. L., Nilsson, M. B., Pastor, J., Eriksson, T., Bergstrom, R. \& Danell, K. (2009). Depression of belowground respiration rates at simulated high moose population densities in boreal forests. Ecology 90, 2724-2733.

Pettorelli, N., Weladji, R. B., Holand, O., Mysterud, A., Breie, H. \& Stenseth, N. C. (2005). The relative role of winter and spring conditions: linking climate and landscapescale plant phenology to alpine reindeer body mass. Biology Letters 1, 24-26.

PigliuCCI, M. \& Marlow, E. T. (2001). Differentiation for flowering time and phenotypic integration in Arabidopsis thaliana in response to season length and vernalization. Oecologia 127, 501-508.

Post, E. \& ForChHAMmer, M. C. (2008). Climate change reduces reproductive success of an Arctic herbivore through trophic mismatch. Philosophical Transactions of the Royal Society B 363, 2369-2375. 
1242 Post, E., Peterson, R. O., Stenseth, N. C. \& McLaren, B. E. (1999). Ecosystem

1243 consequences of wolf behavioural response to climate. Nature 401, 905-907.

1244 Post, E., Stenseth, N. C., LangVatn, R. \& Fromentin, J. M. (1997). Global climate change 1245 and phenotypic variation among red deer cohorts. Proceedings of the Royal Society of $1246 \quad$ London B 264, 1317-1324.

1247 Potter, K. A., Woods, H. A. \& Pincebourde, S. (2013). Microclimatic challenges in global 1248 change biology. Global Change Biology, n/a-n/a.

1249 Prior, K. M., Dzurisin, J. D. K., Pelini, S. L. \& Hellmann, J. J. (2009). Biology of larvae and 1250 adults of Erynnis propertius at the northern edge of its range. Canadian Entomologist $1251 \quad \mathbf{1 4 1}, 161-171$.

1252 Regehr, E. V., LunN, N. J., Amstrup, S. C. \& Stirling, L. (2007). Effects of earlier sea ice 1253 breakup on survival and population size of polar bears in western Hudson bay. Journal of 1254 Wildlife Management 71, 2673-2683.

1255 RÉGNière, J. \& BENTZ, B. (2007). Modeling cold tolerance in the mountain pine beetle, 1256 Dendroctonus ponderosae. Journal of Insect Physiology 53, 559-572.

1257 Reid, D. G., Bilodeau, F., Krebs, C. J., Gauthier, G., Kenney, A. J., Gilbert, B. S., Leung, 1258 M. C. Y., DuCHESNE, D. \& HofER, E. (2012). Lemming winter habitat choice: a snow1259 fencing experiment. Oecologia 168, 935-946.

1260 Robbins, C. T., Lopez-Alfaro, C., Rode, K. D., Toien, O. \& Nelson, O. L. (2012).

1261 Hibernation and seasonal fasting in bears: the energetic costs and consequences for polar 1262 bears. Journal of Mammalogy 93, 1493-1503.

1263 Roland, J. \& MATTER, S. F. (2013). Variability in winter climate and winter extremes reduces 1264 population growth of an alpine butterfly. Ecology 94, 190-199. 
1265 RUEL, J. J. \& AYRES, M. P. (1999). Jensen's inequality predicts effects of environmental 1266 variation. Trends in Ecology \& Evolution 14, 361-366.

1267

Santiago, A., Herranz, J. M., Copete, E. \& Ferrandis, P. (2013). Species-specific 1268 environmental requirements to break seed dormancy: implications for selection of 1269 1270 1271 1272 1273 1274 1275 1276 regeneration niches in three Lonicera (Caprifoliaceae) species. Botany-Botanique 91, $225-233$.

Schmidt, N. M., Ims, R. A., Hoye, T. T., Gilg, O., Hansen, L. H., Hansen, J., Lund, M., Fuglei, E., ForChHAMMER, M. C. \& SitTLER, B. (2012). Response of an arctic predator guild to collapsing lemming cycles. Proceedings of the Royal Society B 279, 4417-4422.

Sears, M. W., Hayes, J. P., Banta, M. R. \& McCormick, D. (2009). Out in the cold: physiological capacity influences behaviour in deer mice. Functional Ecology 23, 774783.

Serrano, E., Granados, J. E., Sarasa, M., Gonzalez, F., Fandos, P., Soriguer, R. C. \& PereZ, J. M. (2011). The effects of winter severity and population density on body stores 1280 1281 1282 1283 in the Iberian wild goat (Capra pyrenaica) in a highly seasonal mountain environment. European Journal of Wildlife Research 57, 45-55.

Sgueo, C., Wells, M. E., Russell, D. E. \& Schaeffer, P. J. (2012). Acclimatization of seasonal energetics in northern cardinals (Cardinalis cardinalis) through plasticity of metabolic rates and ceilings. Journal of Experimental Biology 215, 2418-2424.

1284 ShEN, K. P. \& HARTE,J. (2000). Ecosystem climate manipulations. In Methods in Ecosystem 1285 Science (ed. O. E. Sala, R. B. Jackson, H. A. Mooney and R. W. Howarth), pp. 353-369. $1286 \quad$ Springer, New York. 
1287 SinCLAIR, B. J. (2001). Field ecology of freeze tolerance: interannual variation in cooling rates, 1288 freeze-thaw and thermal stress in the microhabitat of the alpine cockroach Celatoblatta 1289 quinquemaculata. Oikos 93, 286-293.

1290 Sinclair, B. J., Stinziano, J. R., Williams, C. M., MacMillan, H. A., Marshall, K. E. \& 1291 STOREY, K. B. (2013). Real-time measurement of metabolic rate during freezing and 1292 thawing of the wood frog, Rana sylvatica: implications for overwinter energy use. 1293 Journal of Experimental Biology 216, 292-302.

1294 Sobek-Swant, S., Crosthwaite, J. C., Lyons, D. B. \& Sinclair, B. J. (2012). Could 1295 phenotypic plasticity limit an invasive species? Incomplete reversibility of mid-winter 1296 deacclimation in emerald ash borer. Biological Invasions 14, 115-125.

1297 SOMERO, G. N. (2010). The physiology of climate change: how potentials for acclimatization and 1298 genetic adaptation will determine 'winners' and 'losers'. Journal of Experimental Biology $1299 \quad \mathbf{2 1 3}, 912-920$.

1300 Sousa, T., Domingos, T., Poggiale, J. C. \& Kooijman, S. (2010). Dynamic energy budget 1301 theory restores coherence in biology. Philosophical Transactions of the Royal Society B 1302 365, 3413-3428.

1303 SpIEgEL-Roy, P. \& GoldschmidT, E. E. (2008). The Biology of Citrus. Cambridge University $1304 \quad$ Press, Cambridge.

1305 Stahl, K., Moore, R. D. \& MCKendry, I. G. (2006). Climatology of winter cold spells in 1306 relation to mountain pine beetle mortality in British Columbia, Canada. Climate Research 1307 32, 13-23. 
1308 StOKs, R. \& De Block, M. (2011). Rapid Growth Reduces Cold Resistance: Evidence from 1309 Latitudinal Variation in Growth Rate, Cold Resistance and Stress Proteins. PLoS ONE 6, $1310 \quad$ e16935.

1311 Sturm, M., Schimel, J., Michaelson, G., Welker, J. M., Oberbauer, S. F., Liston, G. E., 1312 FAHNESTOCK, J. \& ROMANOVSKY, V. E. (2005). Winter biological processes could help 1313 convert arctic tundra to shrubland. Bioscience 55, 17-26.

1314 Sutherst, R. W. \& MAyWALD, G. (2005). A climate model of the red imported fire ant, 1315 Solenopsis invicta Buren (Hymenoptera : Formicidae): Implications for invasion of new 1316 regions, particularly Oceania. Environmental Entomology 34, 317-335.

1317 Symon, C., Arris, L. \& Heal, B. (2005). Arctic Climate Impact Assessment. Cambridge $1318 \quad$ University Press, New York.

1319 Tattersall, G. J. \& Ultsch, G. R. (2008). Physiological ecology of aquatic overwintering in 1320 ranid frogs. Biological Reviews 83, 119-140.

1321 TAuber, M. J., TAuber, C. A. \& MASAKI, S. (1986). Seasonal Adaptations of Insects. Oxford $1322 \quad$ University Press, New York.

1323 Thackeray, S. J., Sparks, T. H., Frederiksen, M., Burthe, S., Bacon, P. J., Bell, J. R., 1324 1325 1326 1327 1328 Botham, M. S., Brereton, T. M., Bright, P. W., Carvalho, L., Clutton-Brock, T., Dawson, A., Edwards, M., Elliott, J. M., Harrington, R., Johns, D., Jones, I. D., Jones, J. T., Leech, D. I., Roy, D. B., Scott, W. A., Smith, M., Smithers, R. J., WINFIELD, I. J. \& WANLESS, S. (2010). Trophic level asynchrony in rates of phenological change for marine, freshwater and terrestrial environments. Global Change Biology 16, 1329 3304-3313. 
1330 Tran, J. K., Ylioja, T., Billings, R. F., Regniere, J. \& Ayres, M. P. (2007). Impact of

1331

1332

1333

1334

1335

1336

1337

1338

1339

1340

1341

1342

1343

1344

1345

1346

1347

1348

1349

1350

1351

1352 minimum winter temperatures on the population dynamics of Dendroctonus frontalis. Ecological Applications 17, 882-899.

Trotter, R. T. \& SHIELDS, K. S. (2009). Variation in Winter Survival of the Invasive Hemlock Woolly Adelgid (Hemiptera: Adelgidae) Across the Eastern United States. Environmental Entomology 38, 577-587.

Turbill, C., Bieber, C. \& RuF, T. (2011). Hibernation is associated with increased survival and the evolution of slow life histories among mammals. Proceedings of the Royal Society B 278, 3355-3363.

Tyler, N. J. C., ForChHAmmer, M. C. \& ØRITSland, N. A. (2008). Nonlinear effects of climate and density in the dynamics of a fluctuating population of reindeer. Ecology 89, 16751686.

VAn Asch, M., Salis, L., Holleman, L. J. M., VAn Lith, B. \& Visser, M. E. (2013). Evolutionary response of the egg hatching date of a herbivorous insect under climate change. Nature Climate Change 3, 244-248.

VAn der Putten, W. H., Macel, M. \& Visser, M. E. (2010). Predicting species distribution and abundance responses to climate change: why it is essential to include biotic interactions across trophic levels. Philosophical Transactions of the Royal Society B-Biological Sciences 365, 2025-2034.

VinCENT, L. A. \& MEKIS, E. (2006). Changes in daily and extreme temperature and precipitation indices for Canada over the twentieth century. Atmosphere-Ocean 44, 177-193.

Virtanen, T., Neuvonen, S. \& Nikula, A. (1998). Modelling topoclimatic patterns of egg mortality of Epirrita autumnata (Lepidoptera: Geometridae) with a geographical 
1353 information system: predictions for current climate and warmer climate scenarios.

1354 Journal of Applied Ecology 35, 311-322.

1355 WALther, G. R. (2010). Community and ecosystem responses to recent climate change.

1356 Philosophical Transactions of the Royal Society B 365, 2019-2024.

1357 Williams, C. M., Hellmann, J. J. \& Sinclair, B. J. (2012a). Lepidopteran species differ in 1358 susceptibility to winter warming. Climate Research 53, 119-130.

1359 Williams, C. M., Marshall, K. E., Macmillan, H. A., Dzurisin, J. D. K., Hellmann, J. J. \& 1360 SINCLAIR, B. J. (2012b). Thermal variability increases the impact of autumnal warming 1361 and drives metabolic suppression in an overwintering butterfly. PLoS ONE 7, e34470.

1362 Williams, S. E., Shoo, L. P., IsaAC, J. L., Hoffmann, A. A. \& Langham, G. (2008). Towards 1363 an Integrated Framework for Assessing the Vulnerability of Species to Climate Change. $1364 \quad$ PloS Biology 6, 2621-2626.

1365 Willis, C. G., Ruhfel, B., Primack, R. B., Miller-Rushing, A. J. \& Davis, C. C. (2008). 1366 Phylogenetic patterns of species loss in Thoreau's woods are driven by climate change. Proceedings of the National Academy of Sciences of the United States of America 105, 17029-17033.

YocCOZ, N. G. \& IMS, R. A. (1999). Demography of small mammals in cold regions: the importance of environmental variability. Ecological Bulletins 47, 137-144.

1371 Yom-Tov, Y., Yom-Tov, S. \& JARrell, G. (2008). Recent increase in body size of the 1372 American marten Martes americana in Alaska. Biological Journal of the Linnean Society $137393,701-707$. 
1374 YU, H. Y., LUEDELING, E. \& XU, J. C. (2010). Winter and spring warming result in delayed 1375 spring phenology on the Tibetan Plateau. Proceedings of the National Academy of 1376 Sciences of the United States of America 107, 22151-22156.

1377 Yu, Z., LiU, S. R., Wang, J. X., Sun, P. S., LiU, W. G. \& HARTLEY, D. S. (2013). Effects of 1378 seasonal snow on the growing season of temperate vegetation in China. Global Change 1379 Biology 19, 2182-2195.

1380 Zhang, G., Zhang, Y., DONG, J. \& XiAO, X. (2013). Green-up dates in the Tibetan Plateau have 1381 continuously advanced from 1982 to 2011. Proceedings of the National Academy of 1382 Sciences of the United States of America 110, 4309-4314. 


\section{Figure Captions}

1385 Figure 1 - Projected winter climate change in terrestrial systems over the next century. Predicted 1386 January (northern hemisphere) or July (southern hemisphere) differences between 2090-2099 1387 and 2000-2009 in (A) mean surface air temperature and (B) total precipitation. Tropical regions $1388\left(23^{\circ} \mathrm{S}\right.$ to $\left.23^{\circ} \mathrm{N}\right)$ that do not experience winter are in grey. Predictions are from the HADCM3 1389 model, A2 scenario (Lowe, 2005); means for each cell over the early time period were subtracted 1390 from the means for the late time period to give projected changes.

1392 Figure 2 - Examples of the effects of changes in air temperature and snowfall on snow depth 1393 and soil temperature during winter. (A) Current climate. Note that snow cover buffers soil 1394 temperatures. (B) increased mean air temperature results in increased soil freeze-thaw cycles 1395 during a mid-winter melt because the soils become exposed to warm air temperatures during the 1396 day and freezing air temperatures at night. (C) scenarios whereby increased air temperature 1397 variability modifies soil freezing. In late fall, an early frost exposes soil to cold air prior to 1398 development of the snowpack. Warm spells in either mid-winter or early spring melt the 1399 snowpack, leaving soils vulnerable to subsequent drops in air temperature. Finally, snow melt 1400 can be accelerated by increased diel air temperature variability. (D) reduced winter precipitation 1401 leads to increased soil freeze-thaw cycles following a mid-winter melt and during spring melt as 1402 a result of reduced snow cover at these times.

1404 Figure 3 - A blueprint for predicting the biological impacts of winter climate change on 1405 terrestrial organisms. Abiotic drivers of winter climate change (black circles) alter physiological, 1406 biotic or abiotic processes (white, light grey and white rectangles respectively) leading to 
1407 biological impacts (white hexagons). Signs on arrows indicate the direction of the relationship, 1408 and can be navigated with reference to Table 1 and examples in the text. The dotted line 1409 indicates that decreases in snow and ice occur in response to increased macroclimatic 1410 temperatures; all other relationships occur within organisms' microclimates.

1412 Figure 4 - The relationship between winter energy use and phenology for dormant organisms. A 1413 longer winter (early onset of or later exit from dormancy) results in higher energy use. Winter 1414 climate change is increasing total energy use through increases in means or variability of 1415 temperatures (effectively elevating the entire surface, not shown), and organisms have responded 1416 to this in three ways: A) increasing the degree of metabolic suppression over winter, and thus 1417 lowering energy costs (e.g. the duskywing caterpillar Erynnis propertius; Williams et al., 2012b); 1418 B) delaying the onset of entry into dormancy, thus reducing the period of pre-winter energy drain 1419 (e.g. the pitcher plant mosquito Wyeomyia smithii; Bradshaw \& Holzapfel, 2001); and C) 1420 advancing the date of exit from dormancy, to take advantage of opportunities to feed and reduce winter energy drain (e.g. the yellow-bellied marmot, Marmota flaviventris; Ozgul et al., 2010).

1423 Figure 5 - Integrating winter processes into growing season biology. This assumes that 1424 reproduction (which determines fitness) occurs in the growing season, but could be modified for 1425 other life histories. The black diamond 'winter' represents the abiotic conditions that are 1426 experienced during winter, and the three white boxes are the outcomes of biological processes 1427 and stresses described in Figure 1 and Table 1. These processes affect post-winter condition, 1428 which affects growing season performance (all growing season processes are combined in this 1429 framework), which in turn determines the pre-winter condition of organisms. The strength and 
1

2

1430 importance of these links will depend on life history and the extent to which summer and winter 1431 stresses exacerbate or negate one another.

1432

1433 Figure 6 - Example of how adding links to account for species interactions and ecosystem

1434 processes that determine seasonal changes in resource availability can extend the integration of

1435 winter processes into growing season biology to the ecosystem scale. This example, simplified

1436 from(based on Sturm et al., 2005), describes how climate warming may drive potential feedbacks

1437 between changes in snow cover, nutrient availability and plant species composition in the Arctic. 
1441 Figure 1

$1442 \quad$ Figure 1

Figure $1 \quad$ Surface temperature

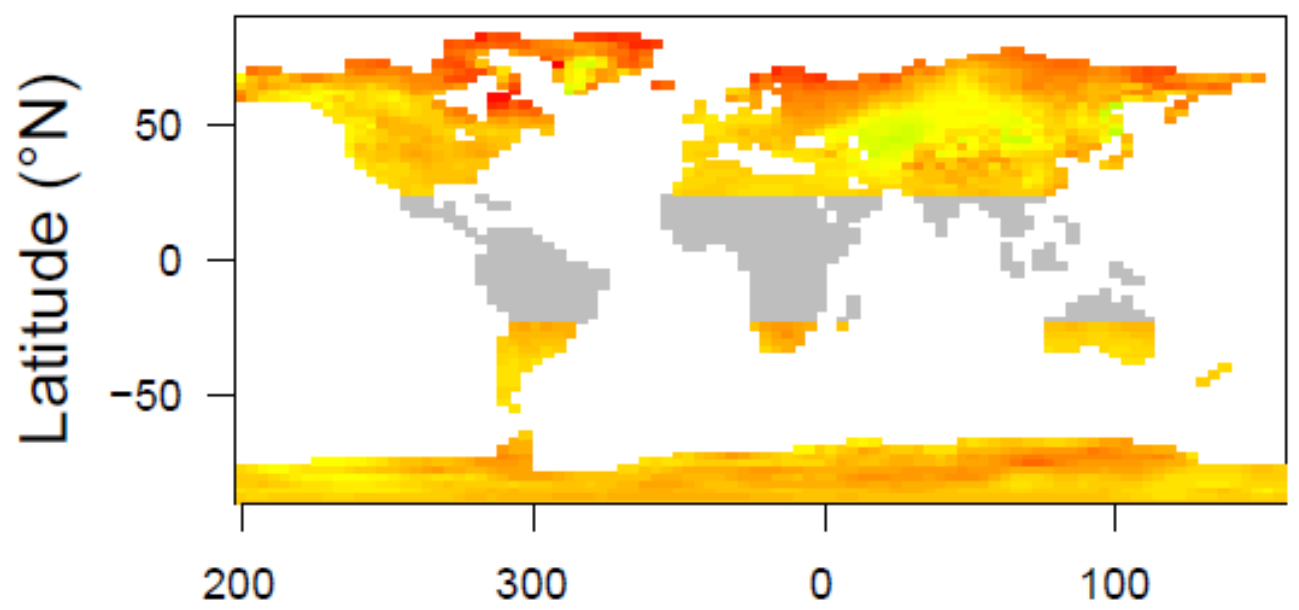

Total precipitation

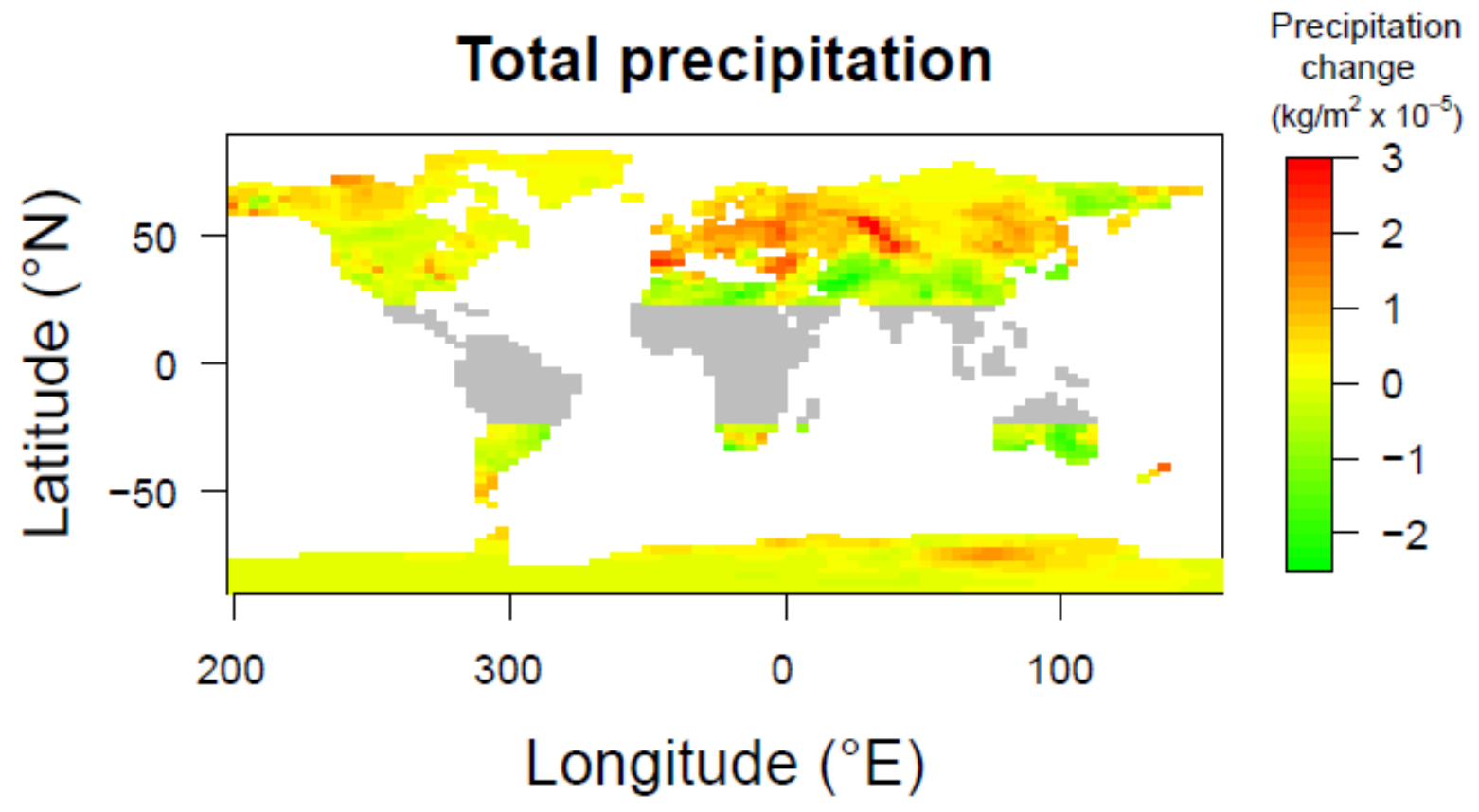

Temperature change

$\left({ }^{\circ} \mathrm{C}\right)$

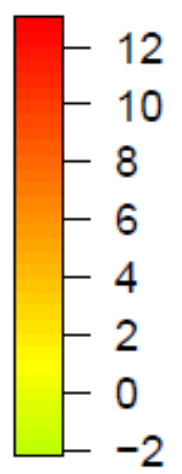

1443

1444 

A. Current climate
B. Increased mean air temperature
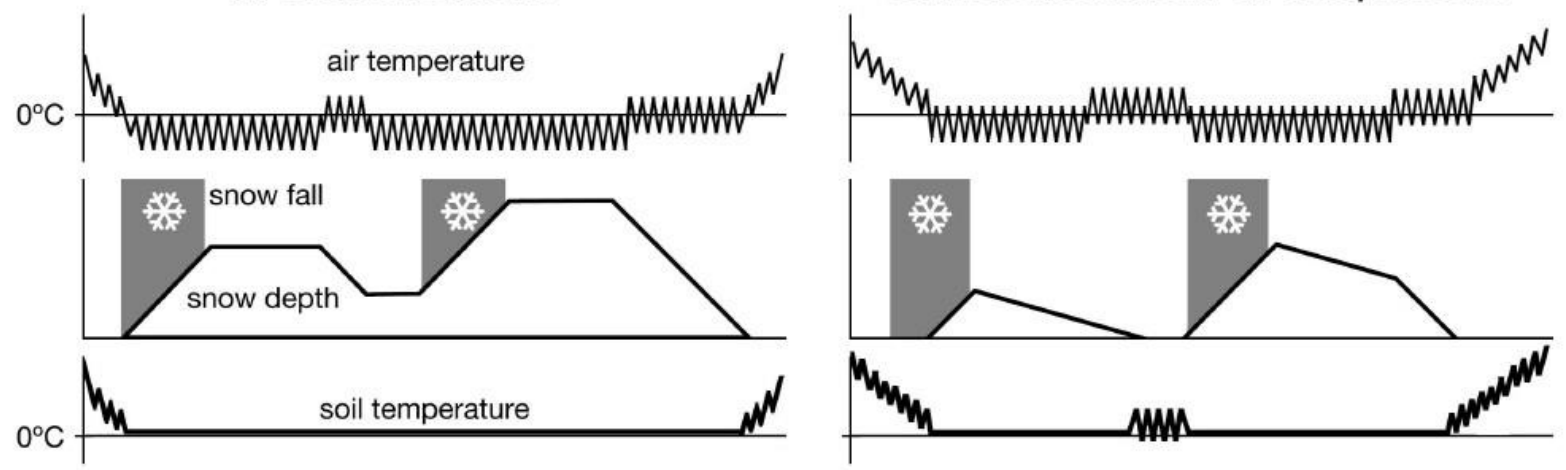

C. Increased air temperature variability

D. Reduced precipitation
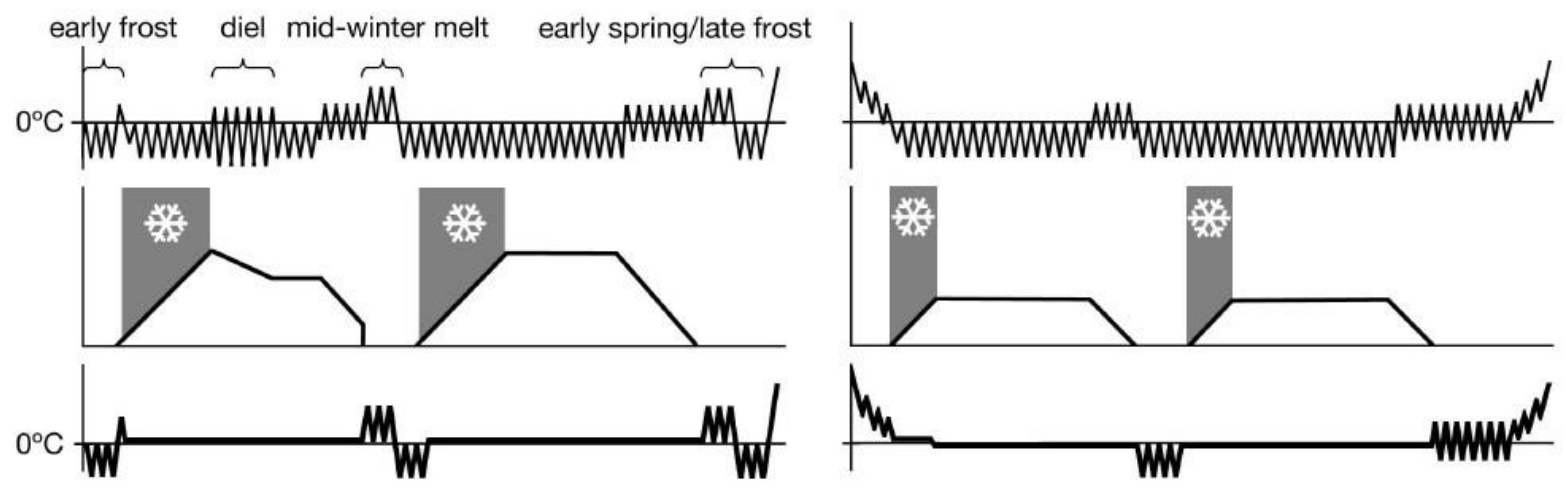

Days 
Figure 3

1452




1455 Figure 4

1456



1457

1458 
1459 Figure 5

1460

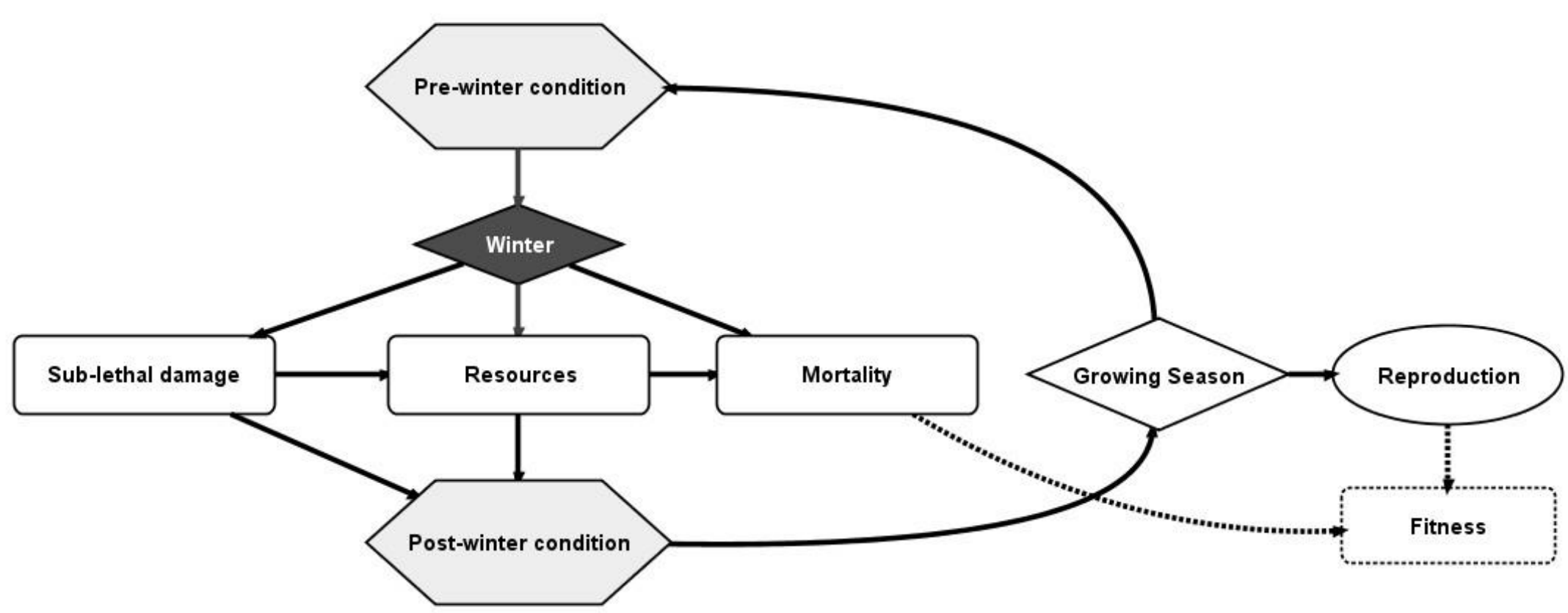

1461

1462

1463

1464 
1465 Figure 6

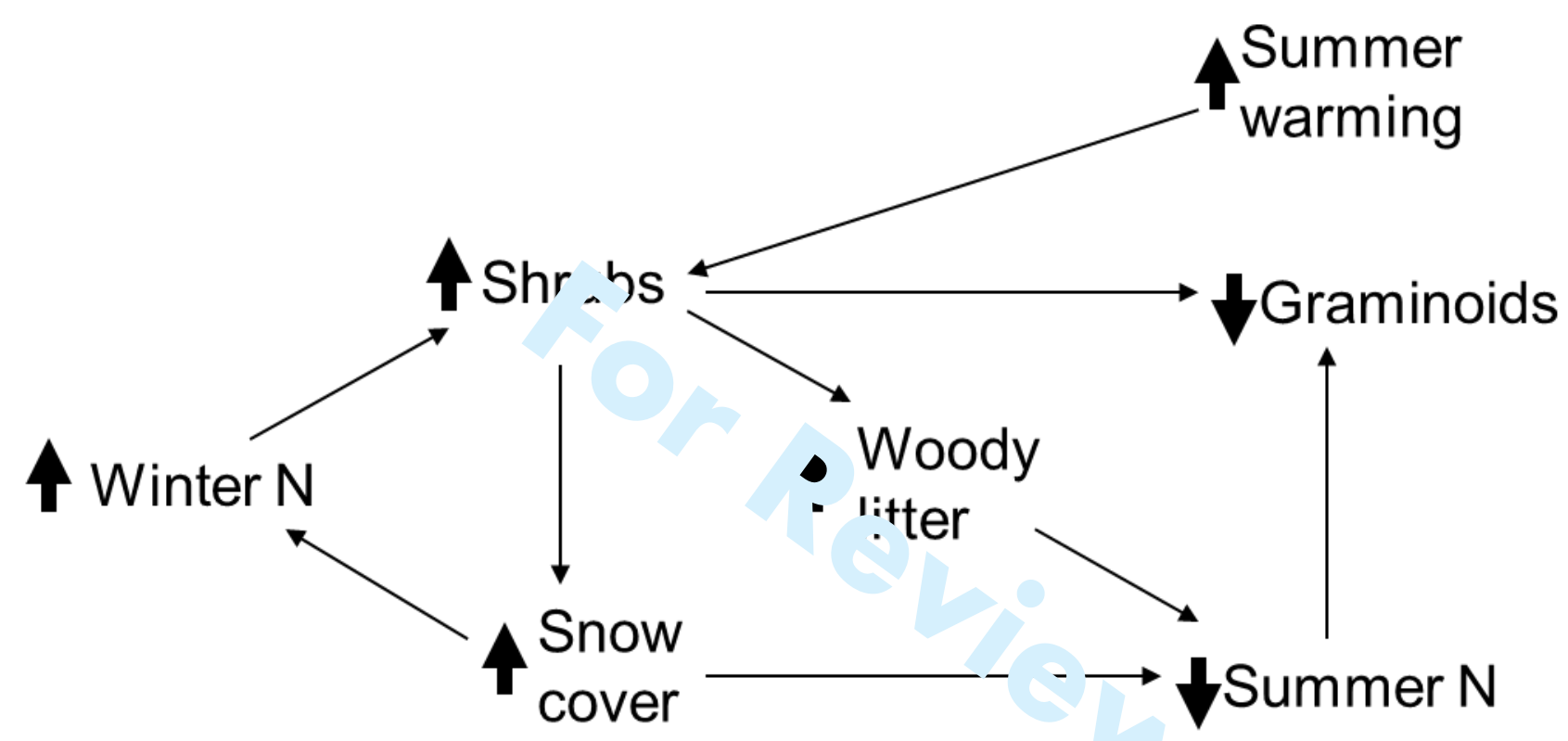


1468 Table 1 - Organismal traits influencing vulnerability to winter climate change. Vulnerability is a product of traits that increase stress 1469 exposure in response to a climate driver and traits that increase sensitivity to this stress, with sensitivity determined by a lack of either 1470 resilience or adaptive potential. Climate drivers (indicated in italics, and with reference to the text and Figure 3) are increased average 1471 temperatures $(A v T)$, thermal variability (subdivided here into increased daily thermal variability $(D V)$, extreme temperatures $(E x T)$ and 1472 increased freeze-thaw cycles $(F / T)$ ), increased snow $(\mathrm{S}+)$ and decreased snow $(S$-).

\section{Traits determining stress exposure Traits determining sensitivity to stress Proximal cause of \\ vulnerability}

\section{Energy balance}

Thermoregulatory strategy $(A v T, D V)$

- poikilotherms > homeotherms

Energy intake and availability $(A v T, D V, S+)$

- no energy intake/limited food available $>$ winter energy uptake

Metabolic suppression $(A v T, D V, S+)$

- low > high suppression

Metabolic plasticity $(A v T, D V)$

- low > high plasticity

Trophic position $(S+)$

- $\quad$ predator $>$ prey

- heterotroph $>$ autotroph

Habitat ( $S$-)

- $\quad$ subnivean $>$ supranivean
Reproductive strategy $(A v T, D V)$

- capital breeding > income

Energy storage $(A v T, D V)$

- low > high pre-winter energy stores

Energetic recovery $(A v T, D V)$

- no post-winter feeding > feeds postwinter

Feeding strategy $(S+, S$-)

- $\quad$ specialist > generalist
- Consumption of finite energy reserves $(A v T$, $D V)$

- Decreased resource availability

- Increased cost of locomotion $(S+)$

- Decreased food access $(S+)$ 
Table 1 (continued)

\begin{tabular}{lcc}
\hline Traits determining stress exposure & Traits determining sensitivity to stress & $\begin{array}{c}\text { Proximal cause of } \\
\text { vulnerability }\end{array}$ \\
\hline Phenology & & Reduction in length of \\
\hline Chilling or vernalization requirements $(A v T)$ & Trophic level $(A v T)$ & growing season $(A v T)$ \\
$\bullet \quad$ obligate $>$ facultative dormancy & $\bullet \quad$ consumers $>$ primary producers & Trophic mismatches ( \\
$\bullet \quad$ chilling requirement $>$ non-thermal & Diet breadth $(A v T)$ & AvT) \\
$\quad$ cues & $\bullet \quad$ low $>$ high & habitat not available for \\
Habitat requirements $(S-)$ & Overwintering stage $(A v T)$ & reproduction $(S$ - $)$
\end{tabular}


Table 1 (continued)

\section{Cold injury}

Cold hardiness $(E x T)$

- cold-susceptible > cold-hardy

Cold tolerance strategy $(E x T)$

- seasonally programmed but readily deacclimate $>$ constitutive protection

Position of biological thresholds (ExT, F/T)

- lower/higher than current conditions > near current conditions

Habitat ( $S$-)

- $\quad$ subnivean $>$ supranivean

\section{Water Balance}

Susceptibility to waterlogging and ice encasement

- hypoxia intolerant $>$ hypoxia tolerant
Rapid cold hardening (ExT)

- none > effective rapid hardening response

Thermal plasticity (ExT)

- no reacclimation > reacclimation

Cumulative impact of repeated stress $(F / T)$

- $\quad$ cumulative $>$ no cumulative

impact/impact reaches asymptote

Water balance strategy

- no winter water consumption > water consumption over winter
- Direct injury from cold (ExT)

- Cumulative cold injury $(F / T)$

- Energetic costs of repairing cold injury $(F / T, S-)$

- Hypoxia from waterlogging/ice encasement

- Unavailability of liquid water when frozen 
Table 1 (continued)

\begin{tabular}{lcc}
\hline Traits determining stress exposure & Traits determining sensitivity to stress & $\begin{array}{c}\text { Proximal cause of } \\
\text { vulnerability }\end{array}$ \\
\hline Predation & Predator avoidance $(S-)$ & Increased mortality \\
\hline Trophic position $(S-)$ & $\bullet \quad$ low camouflage plasticity $>$ low & low defenses $>$ high \\
$\bullet \quad$ prey $>$ predator & $\bullet$ & high palatability $>$ low \\
Habitat $(S-)$ & - low alertness $>$ high \\
$\qquad \quad$ subnivian $>$ supranivean &
\end{tabular}


1478 Table 2 - The range of effects of changes in the quantity and timing of snow cover on overwintering organisms.

1479

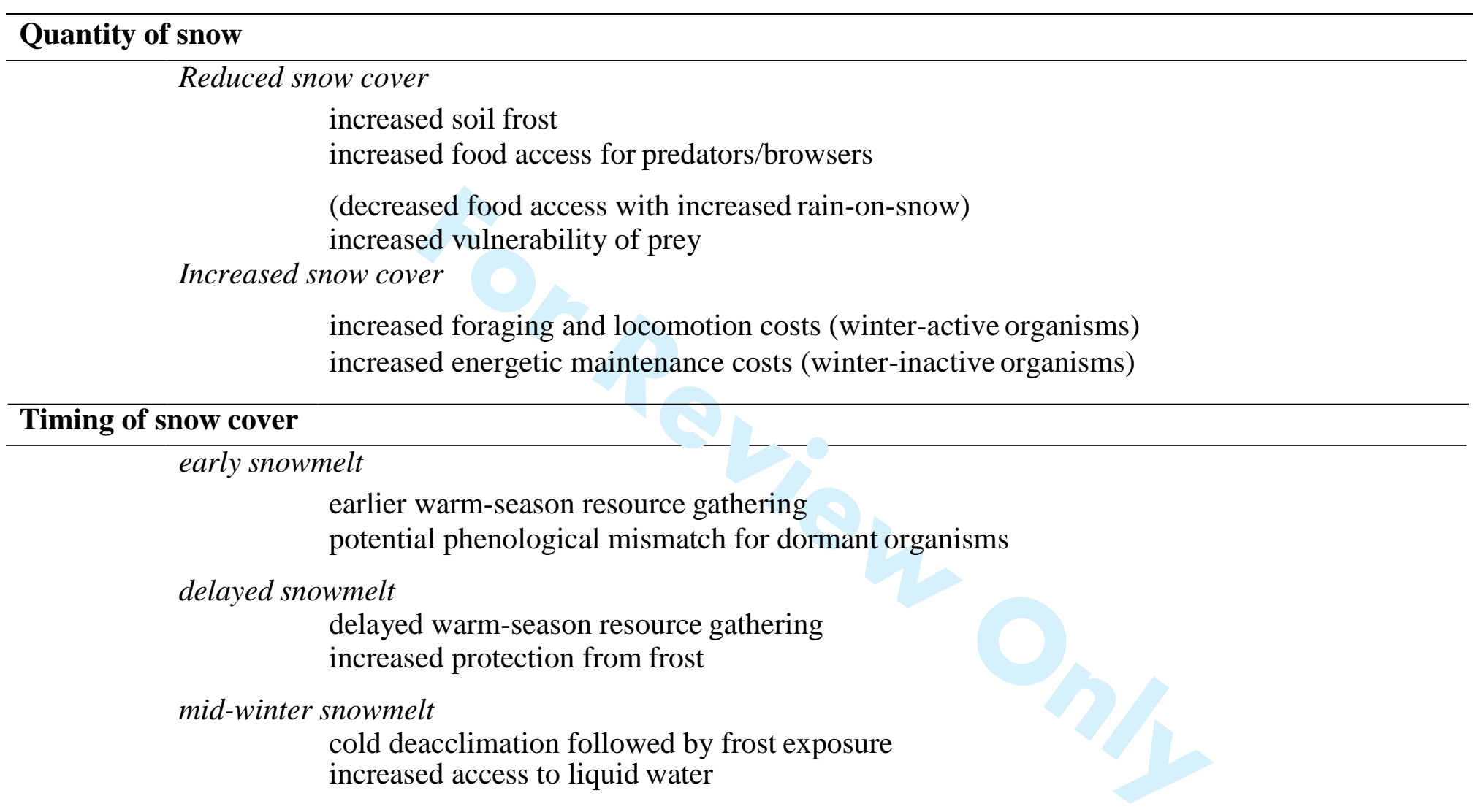

1480

1481 